\title{
A revision of European Plesiosminthus (Rodentia, Dipodidae), and new material from the upper Oligocene of Teruel (Spain)
}

\author{
Matthijs Freudenthal and Elvira Martín-Suárez
}

\begin{abstract}
The European record of the rodent genus Plesiosminthus is revised, and two new species are described. Plesiosminthus promyarion is found to be a nomen dubium in the sense of the International Code of Zoological Nomenclature and that name should therefore no longer be used. Until now the genus was hardly known from localities older than MP28; for the first time we describe rich samples from the upper Oligocene (MP 27) of Spain. By now, 10 European species are known, one from the lower Miocene, and the other ones from the upper Oligocene. For most of them it is not possible to establish ancestor-descendant relationships.
\end{abstract}

Matthijs Freudenthal. Departamento de Estratigrafía y Paleontología, Universidad de Granada, Avda. Fuentenueva s/n, E-18071 Granada, Spain; Naturalis Biodiversity Center, P.O. Box 9517, NL-2300 RA Leiden, The Netherlands. mfreuden@ugr.es

Elvira Martín-Suárez. Departamento de Estratigrafía y Paleontología, Universidad de Granada, Avda. Fuentenueva s/n, E-18071 Granada, Spain. elvirams@ugr.es

Keywords: Mammalia; Dipodidae; Oligocene; Miocene; new species

Submission: 6 May 2016 Acceptance: 11 August 2017

\section{INTRODUCTION}

The genus Plesiosminthus (Rodentia, Dipodidae) was created by Viret, 1926 for the species $P$. schaubi from Coderet, France. In 1930 Schaub added two new species: $P$. myarion and $P$. promyarion. In 1941 Freudenberg described P. bavaricus from Gaimersheim, Germany. Hugueney and
Vianey-Liaud (1980) described a number of new samples from France, all of which were attributed to the already known species, and these authors put $P$. bavaricus in synonymy with $P$. promyarion. From 1987 onwards several new species have been described and by now 10 different species are known from the European Oligocene and Miocene, including the two new species described in

http://zoobank.org/A085E4EE-97FA-4BB7-AE08-C1674AADAF40

Freudenthal, Matthijs and Martín-Suárez, Elvira. 2017. A revision of European Plesiosminthus (Rodentia, Dipodidae), and new material from the upper Oligocene of Teruel (Spain). Palaeontologia Electronica 20.2.41A: 1-25 palaeo-electronica.org/content/2017/1973-european-plesiosminthus

Copyright: August 2017 Society for Vertebrate Paleontology. This is an open access article distributed under the terms of the Creative Commons Attribution License, which permits unrestricted use, distribution, and reproduction in any medium, provided the original author and source are credited. creativecommons.org/licenses/by/4.0/ 
this work. Apart from these, several species have been mentioned or described in open nomenclature. In Table 1 the European species of Plesiosminthus are listed. The oldest occurrences of the genus are: Seven teeth from La Devèze, France (MP26 according to Biochrom, 1997), mentioned by Hugueney and Vianey-Liaud (1980) as P. promyarion. One tooth of Plesiosminthus sp. (Engesser and Mödden, 1997) from Mümliswil-Hardberg, Switzerland (MP26 according to Engesser and Mödden; MP27 according to Biochrom, 1997). A doubtful occurrence is reported from Mirambueno 4C and Mirambueno 4D, Spain (MP26) by Freudenthal (1997); no teeth were found, only some fragments of grooved incisors, which are relatively large for Plesiosminthus. Freudenthal (1997) considered the possibility that they belong to the glirid Gliravus (now Butseloglis Vianey-Liaud, 2004).

In this paper a new species, P. margaritae $\mathrm{n}$. sp., is described from the upper Oligocene (MP27) of Mirambueno 1, Spain. Another species, from Mirambueno 2A, Spain, is described as $P$. aff. conjunctus. They represent the second oldest representatives of the genus. Hugueney and VianeyLiaud (1980) described P. promyarion from Pech Desse, France; we transfer that sample to $P$. moniqueae $\mathrm{n}$. sp. European Plesiosminthus may be divided into two overlapping size groups: the larger species like $P$. schaubi, $P$. winistoerferi and $P$. admyarion, and smaller species like $P$. myarion, $P$. promyarion, $P$. moniqueae n. sp., $P$. bavaricus, $P$. conjunctus, $P$. moralesi, $P$. meridionalis, and $P$. margaritae $\mathrm{n}$. sp. The large-sized group is not represented in our material. Furthermore there are a few records, described in open nomenclature, of a very small-sized group.

\section{MATERIAL AND METHODS}

Our material comes from three Spanish localities: Mirambueno 1 (MIR1), Mirambueno 2A (MIR2A), and Vivel del Río 1 (VIV1); storage location and catalogue numbers are as follows.

Collection Naturalis (Leiden, the Netherlands, former Rijksmuseum van Geologie en Mineralogie, RGM): MIR1: 214 specimens, RGM 558094558307; MIR2A: 102 specimens, RGM 558532558633; VIV1: 224 specimens, RGM 558308558531.

Collection Museo de Ciencias Naturales, Universidad de Zaragoza: 35 specimens, MIR1 164197, 228; 37 specimens, MIR2A 82-118; 106 specimens, VIV1 514-619.

These localities are located on topographic map 1:50,000, 27-19, Segura de los Baños. Their UTM (Universal Transverse Mercator) coordinates (datum point European Datum 1950 (ED50), as used on the printed map) are: Zone 30T; MIR1: 0675545/4524770; MIR2A: 0675404/4524803; MIR4: 0676048/4524496; VIV1: 0674649/ 4525328.

The Cricetidae from these localities have been described by Freudenthal (1994) and Freudenthal et al. (1994); provisional faunal lists were published by Freudenthal (1997).

The terminology used (Figure 1 ) is as in Cricetidae (Freudenthal et al., 1994), with a few additions: anterostyle, a cusp at the labial end of

TABLE 1. Species of Plesiosminthus described from the European Oligocene and Miocene.

\begin{tabular}{ll}
\multicolumn{1}{c}{ Species } & \multicolumn{1}{c}{ Type-locality } \\
\hline P. schaubi Viret, 1926 (type-species) & Coderet, France \\
P. myarion Schaub, 1930 & Chavroches, France \\
P. promyarion Schaub, 1930 & Puy-de-Montdoury, France \\
P. bavaricus Freudenberg, 1941 & Gaimersheim, Germany \\
P. winistoerferi Engesser, 1987 & Brochene Fluh 53, Switzerland \\
P. conjunctus Ziegler, 1994 & Herrlingen 8, Germany \\
P. moralesi Álvarez Sierra, Daams and Lacomba Andueza, 1996 & Sayatón 1, Spain \\
P. admyarion Comte, 2000 & Thézels, France \\
P. meridionalis Comte, 2000 & Venelles inf., France \\
P. margaritae n. sp. (this paper) & Mirambueno 1, Spain \\
P. moniqueae n. sp. (this paper) & Pech Desse, France \\
Plesiosminthus n. sp., Ziegler, 1994 & Herrlingen 8, Germany \\
Plesiosminthus sp., Engesser and Mödden, 1987 & Mümliswil-Hardberg, Switzerland \\
Plesiosminthus sp., Comte, 2000 & Venelles inf., France \\
\hline
\end{tabular}



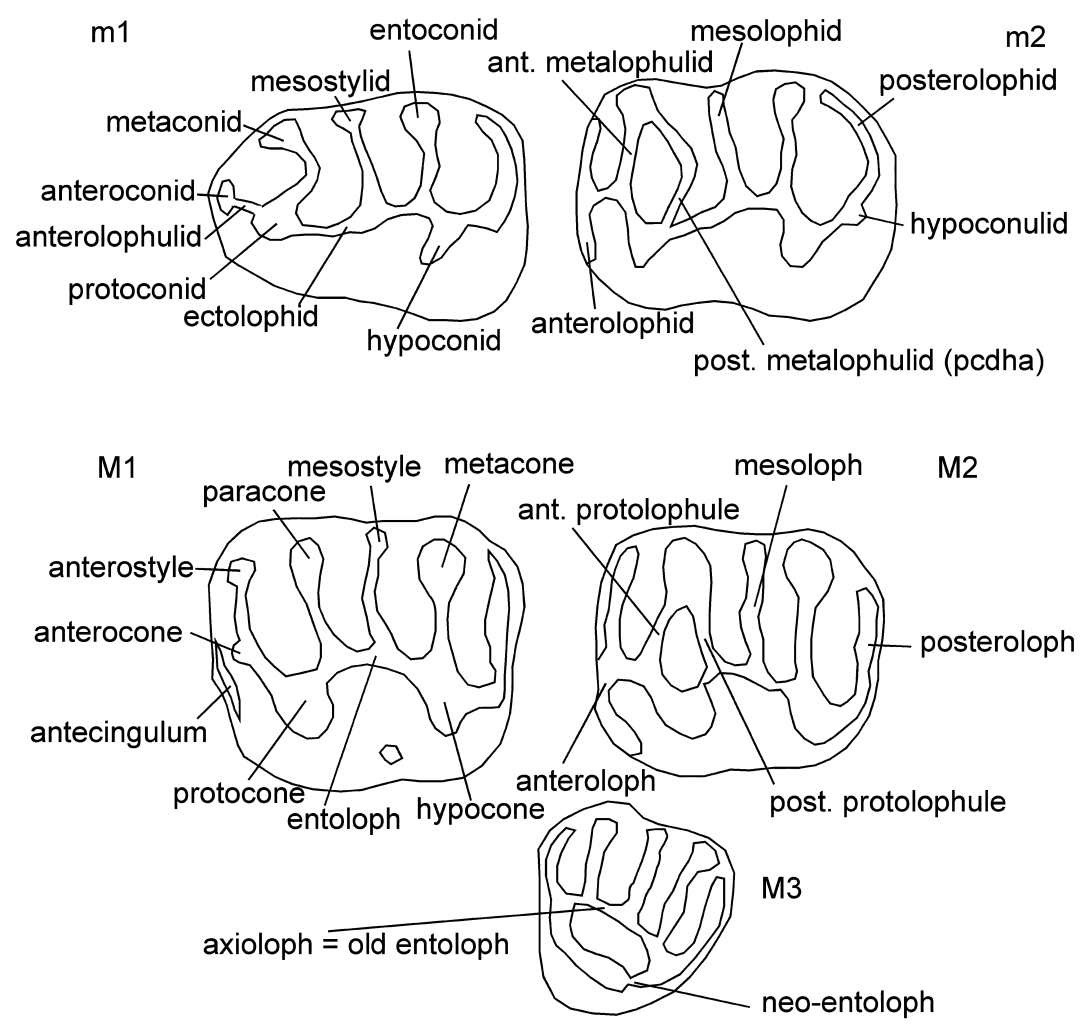

FIGURE 1. Terminology of molars. Figures represent left-hand molars.

the anteroloph in $\mathrm{M} 1$; antecingulum, a cingulum ridge at the base of the anteroloph in M1.

$V^{\prime}$ is the coefficient of variation (Range divided by median) as defined by Freudenthal and Cuenca Bescós (1984).

Photographs were taken on the electron microscope FEI ESEM QUANTA 400 of the 'Centro de Instrumentación Científica' of the University of Granada.

Measurements were taken with a Wild M8 binocular microscope, equipped with a mechanical stage with electronic sensors, connected to a computer through a Sony Magnescale measuring unit. The measurement data were processed using a private computer program, written in Visual Basic. Measurements are given in $\mathrm{mm}$.

Locality codes are explained in Table 2 . Other abbreviations are: pcdha = protoconid hind arm; $\mathrm{m} 1, \mathrm{~m} 2, \mathrm{~m} 3$ = lower molars; M1, M2, M3 = upper molars.

For some characters morphology values (MV) have been calculated (see Freudenthal, 2004), using the equation

$$
M V=\Sigma(n-1) f_{n} /(C-1) \Sigma f_{n},
$$

where $C$ is the number of character states, and $f_{n}$ is the observed frequency for the nth character state. For example, if four character states are distinguished, the consecutive states score $0,0.333$, 0.666 , and 1.0 , respectively. The scores of all specimens are summed up, and the result is divided by the total number of specimens, leading to a value between 0 and 1 . MV is typically useful for features, that in fact have a continuous size representation, e.g., for a length: absent/short /medium/ long, and is an approximation of actually measuring the parameter in each specimen, and calculating the mean of the measurements. It may be calculated on actual numbers of specimens, or on percentages; in the latter case $\Sigma f_{n}=100$.

\section{SYSTEMATIC PALAEONTOLOGY}

Order Rodentia Bowdich, 1821

Family Dipodidae Fischer, 1817

Genus PLESIOSMINTHUS Viret, 1926

Remarks. Many authors give Fischer de Waldheim or Fischer von Waldheim as author of the family Dipodidae. However, Hutterer (2003) stated: "Fischer was elevated to nobility in 1835 , and then 
TABLE 2. Locality codes, species contents and most important reference of the localities studied. Zones are European mammal zones (Biochrom'97, 1997).

\begin{tabular}{|c|c|c|c|c|}
\hline Code & Locality & Zone & Species & Reference \\
\hline BF53 & Brochene Fluh 53 & MP30 & P. winistoerferi & Engesser (1987) \\
\hline CANAL & Canales & MP28 & Plesiosminthus sp. & Alvarez Sierra et al. (1999) \\
\hline CHAVR & Chavroches & MN2 & P. myarion & Hugueney and Vianey-Liaud (1980) \\
\hline CLUZEL & Cluzel & MN2 & P. myarion & Hugueney and Vianey-Liaud (1980) \\
\hline COD3 & Coderet 3 & MP30 & P. schaubi & Hugueney (1969) \\
\hline DIEU & Dieupentale & MP30 & P. schaubi & Baudelot and Olivier (1978) \\
\hline FORN11 & Fornant 11 & MN1 & P. myarion & Engesser (1987) \\
\hline GAIM & Gaimersheim & MP28 & P. bavaricus & Kristkoiz (1992) \\
\hline HERR8 & Herrlingen 8 & MP28 & P. conjunctus & Ziegler (1994) \\
\hline LAUT2 & Lautern 2 & MN1 & P. myarion & Ziegler and Werner (1994) \\
\hline MIR1 & Mirambueno 1 & MP27 & P. margaritae & this paper \\
\hline MIR2A & Mirambueno $2 \mathrm{~A}$ & MP27 & $P$. aff. conjunctus & this paper \\
\hline OBL & Oberleichtersbach & MP30 & P. winistoerferi & Engesser and Storch (2008) \\
\hline PARR & Parrales & MP29 & P. schaubi & Alvarez Sierra et al. (1999) \\
\hline PDES & Pech Desse & MP28 & P. promyarion & Hugueney and Vianey-Liaud (1980) \\
\hline PDES & Pech Desse & MP28 & P. moniqueae & this paper \\
\hline PDF & Pech-du-Fraysse & MP28 & P. promyarion & Hugueney and Vianey-Liaud (1980) \\
\hline RDUBEY & Ruisseau du Bey & MP28 & P. promyarion & Engesser (1987) \\
\hline SAULC & Saulcet & MN1 & P. myarion & Hugueney and Vianey-Liaud (1980) \\
\hline SAY1 & Sayatón 1 & MP29 & P. moralesi & Alvarez et al. (1996) \\
\hline $\mathrm{THZ}$ & Thézels & MP30 & P. admyarion & Comte (2000) \\
\hline VENINF & Venelles inf. & MP30 & P. meridionalis & Comte (2000) \\
\hline VIV1 & Vivel del Río 1 & MP28 & P. cf. margaritae & this paper \\
\hline
\end{tabular}

adopted the title von Waldheim. His earlier work should be cited as Fischer."

Type species. Plesiosminthus schaubi Viret, 1926.

Plesiosminthus promyarion Schaub, 1930

Type locality. Puy-de-Montdoury, MP 28, France. Holotype. Schaub (1925) classified two m3 from Puy-de-Montdoury as ?Cricetodon spec. One is extremely worn and was not described. $\mathrm{He}$ described the other one (Au 1214) in detail and figured it (Schaub, 1925, plate 2, figure 10). Later, Schaub (1930) placed the two aforementioned m3 from Puy-de-Montdoury in a new species, Plesiosminthus promyarion, whose type material also includes a M2 with double protolophule from Rickenbach, Germany. Schaub (1930) did not designate a holotype. Hugueney and Vianey-Liaud (1980) designated the specimen Au 1214 as the holotype, but in fact it is a lectotype. Such type material is clearly insufficient to define a species of Plesiosminthus, or, in other words, P. promyarion is a nomen dubium in the sense of article 75.5 of the International Code of Zoological Nomenclature.
The first exhaustive description of $P$. promyarion is by Hugueney and Vianey-Liaud (1980). These authors recognized the insufficiency of the type material, and therefore introduced the sample from Pech Desse as reference for $P$. promyarion. What they did in fact was change the concept of the species $P$. promyarion, coining the name to a different sample. Furthermore, they placed $P$. bavaricus Freudenberg, 1941 from Gaimersheim, poorly known at the time, in synonymy with $P$. promyarion.

Since the paper by Hugueney and VianeyLiaud (1980) our knowledge of Plesiosminthus has increased, and several new species have been described. Particularly important is the redescription of an enlarged collection from Gaimersheim by Kristkoiz (1992). That author maintained the synonymy of $P$. bavaricus and $P$. promyarion, but here we will show that the samples from Gaimersheim and Pech Desse represent different species. That means that it is impossible to know whether the type material of $P$. promyarion belongs to $P$. bavaricus or to the species from Pech Desse. The best 
solution is to create a new name for the Pech Desse material and restrict $P$. promyarion to the type material.

Hugueney and Vianey-Liaud (1980) attributed a sample from Pech-du-Fraysse to the same species as the one from Pech Desse. However, it seems to represent a different species since four of the six figured M2 from Pech-du-Fraysse have a posterior protolophule besides the anterior one. Furthermore, in Pech Desse the mesolophid of m3 is nearly always long, never absent, whereas in PDF it is shorter and may be absent. Also, the antecingulum of M1 is nearly always present in the latter locality. The width of M1 and of the lower molars is significantly larger in PDF than in PDES.

Insufficiently described samples have been reported from Ruisseau du Bey, Switzerland (Engesser, 1987), Cournon, and La Devèze, both in France (Hugueney and Vianey-Liaud, 1980). We provisionally refer to these samples and to the one from PDF as $P$. promyarion Auctorum, since it is impossible to know to what species they belong.

Plesiosminthus promyarion has been reported from Vivel del Río (Hugueney et al., 1987). We transfer that sample to $P$. cf. margaritae n. sp. (see below).

\section{Plesiosminthus moniqueae n. sp.}

zoobank.org/0154335C-6C9E-4F15-9ABD-3C64C0CECFF7

Type locality. Pech Desse, MP28, Quercy, France. Holotype. M2 sin., PDS 510, Hugueney and Vianey-Liaud (1980, plate 4g).
Measurements. Appendix 1 (from Hugueney and Vianey-Liaud, 1980).

Derivatio nominis. In honour of Dr. Monique Vianey-Liaud, co-author of the first monographic paper on Plesiosminthus after the study by Schaub (1930).

Diagnosis. Based on data in Hugueney and Vianey-Liaud (1980); In $\mathrm{m} 1$ the anteroconid is isolated and the mesostylid is well developed; the ectolophid is rarely interrupted at the protoconid. In $\mathrm{m} 2$ the protoconid hind arm (or posterior metalophulid) is complete in $30 \%$, absent in about $20 \%$ of the specimens, and incomplete in the rest; in $\mathrm{m} 3$ it is absent in about $30 \%$ and complete or incomplete in the rest. M1 and M2 almost equal in length. In M1 the mesostyle is well developed; in $33 \%$ of the specimens, there is an anterostyle and a cingulum in front of the anteroloph. In M2 the protolophule is anterior and a posterior connection is rarely present.

Differential diagnosis. Plesiosminthus moniqueae $\mathrm{n}$. sp. from Pech Desse differs from most other species (except for $P$. schaubi and $P$. admyarion) by the rarely present posterior protolophule in M2 (morphology value MV $=0.195$; see Table 3 and Figure 2). It differs from $P$. schaubi and $P$. admyarion by its smaller size.

Plesiosminthus bavaricus Freudenberg, 1941

Type locality. Gaimersheim, MP28, Germany. Synonymy. Plesiosminthus promyarion in Kristkoiz (1992).

Holotype. Not designated, but marked as holotype in the Munich collection: Mandibula dext. with m1-

TABLE 3. Frequencies of character states of the protolophule of M2, number of observations, and morphology values. Ant. = anterior, trans = transverse, ant.plus = anterior plus an incomplete posterior connection. * protolophule posterior, not double.

\begin{tabular}{lccccc}
\hline \multicolumn{1}{c}{ Sample } & ant. or trans & ant. plus & double & $\mathbf{n}$ & MV \\
\hline CHAVR & 0 & 3 & 97 & 33 & 0.985 \\
FORN11 & & & & & \\
VENINF & 4 & 0 & $96^{*}$ & 25 & 0.960 \\
THZ & 95 & 0 & 5 & 97 & 0.050 \\
COD3 & 97 & 0 & 3 & 63 & 0.032 \\
HERR8 & 17 & 8 & 75 & 12 & 0.790 \\
PDF & & & & & \\
GAIM & 39 & 52 & 9 & 23 & 0.350 \\
PDES & 74 & 13 & 13 & 16 & 0.195 \\
RDUBEY & & & & & \\
VIV1 & 57 & 4 & 39 & 69 & 0.410 \\
MIR2A & 19 & 7 & 74 & 27 & 0.775 \\
MIR1 & 28 & 37 & 35 & 43 & 0.535 \\
\hline
\end{tabular}




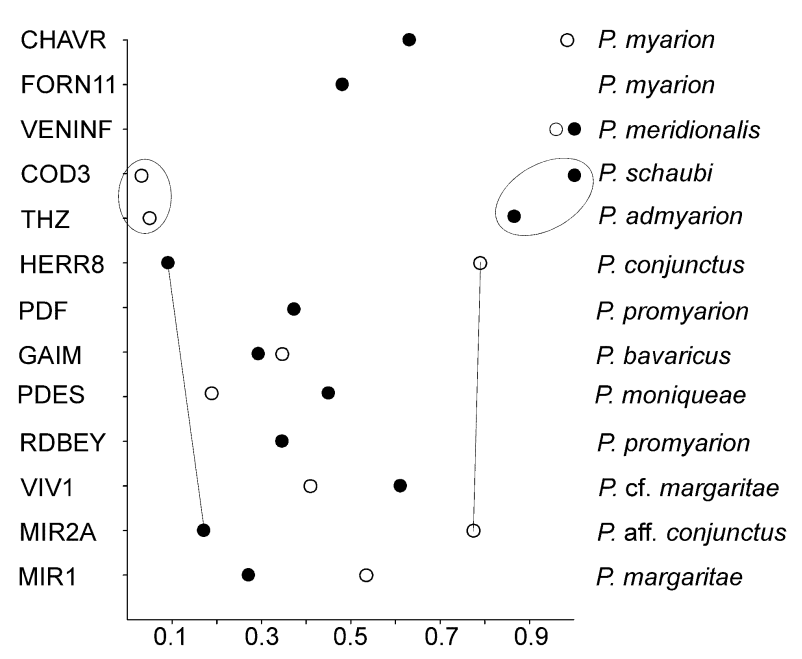

FIGURE 2. Distribution of morphology values of protoconid hind arm in $\mathrm{m} 2$ (filled circles) and protolophule in M2 (open circles). Enclosing circles and connecting lines indicate possible relationships.

m3, SNSB-BSPG 1939 XI 23, figured in Freudenberg (1941, figure 8 and plate 12, figure 17) and Kristkoiz (1992, plate 1, figure c) (information kindly provided by Dr. G. Roessner, Munich).

Measurements. Appendix 1 (from Kristkoiz, 1992). Emended diagnosis. Extracting the most important features from Kristkoiz (1992) we propose the following diagnosis: in $\mathrm{m} 1$ the anteroconid is isolated and the mesostylid is weakly developed; the protoconid hind arm is nearly always bent, rarely straight; the ectolophid is rarely interrupted at the protoconid; an ectostylid or cingulum is present in the sinusid in about half the cases. In $\mathrm{m} 2$ the protoconid hind arm (or posterior metalophulid) is complete in $50 \%$ of the specimens. In $\mathrm{m} 3$ the protoconid hind arm is generally absent and the mesolophid is nearly always long, reaching the molar border. In M1 an antecingulum is rarely present, the mesostyle is small. In M2, besides the anterior one, the posterior protolophule is present in more than half the cases, either interrupted or rarely complete; the entoloph is never connected to the protocone.

Plesiosminthus bavaricus differs from $P$. moniqueae n. sp. by: the less frequent ectostylid/ cingulum in $\mathrm{m} 1$ ( $44 \%$ vs. $93 \%$ ); the better developed protoconid hind arm in $\mathrm{m} 2$; the less frequent antecingulum in $\mathrm{M} 1$; the poorly developed mesostyle in M1, which is always well developed in Pech Desse; the more frequent posterior protolophule in M2.

\section{Plesiosminthus margaritae n. sp.}

Figure 3.1-12

zoobank.org/9B1B48B8-7527-453D-9031-F0D850E9627B

Type locality. Mirambueno 1, MP27, Spain.

Holotype. M2 dext., MIR1 193, Museo de Ciencias Naturales, Universidad de Zaragoza.

Material. Collection Naturalis-Leiden: 21 m1, RGM 558094-558114; 32 m2, RGM 558115-558146; 41 m3, RGM 558147-558187; 1 P4, RGM 558307; 49 M1, RGM 558188-558236; 36 M2, RGM 558237558272; 33 M3, RGM 558273-558306. Collection Zaragoza: $2 \mathrm{~m} 1$, MIR1 164-165; $11 \mathrm{~m} 2$, MIR1 166-176; 4 m3, MIR1 177-180; 8 M1, MIR1 181188; 7 M2, MIR1 189-195; 3 M3, MIR1 196-197, 228.

Measurements. Appendix 1, Figure 4.

Derivatio nominis. In honour of Dr. Marguerite Hugueney, co-author of the first monographic paper on Plesiosminthus after the study by Schaub (1930).

Diagnosis. Anteroconid of $\mathrm{m} 1$ small, without an anterolophulid. Ectolophid oblique. Mesoconid and mesostylid generally absent; when present, poorly developed. Protoconid hind arm of $\mathrm{m} 2$ transverse and low connected to the metaconid in half the cases, may be absent or short, or of medium length. Ectolophid oblique or, less frequently, longitudinal. Mesoconid and mesostylid like in $\mathrm{m} 1$. Protoconid hind arm in $\mathrm{m} 3$ the predominantly absent, mesolophid generally long, may reach the border of the molar. Anterocone, anterostyle, and mesostyle in M1 generally absent. Protolophule in M2 anterior, frequently accompanied by a - complete or incomplete posterior connection.

Description. Number of specimens in brackets.

m1-anteroconid absent (3), small (11), or with cingulum (3); anterolophulid absent; metalophulid absent; protoconid hind arm transverse and low connected to the metaconid (4), transverse and high connected to the metaconid (9), bent and low connected to the metaconid (1), or bent and high connected to the metaconid (8); ectolophid longitudinal (1) or oblique (22); ectolophid complete (14), anteriorly interrupted (6), or isolated (2); mesoconid absent (16) or weak (4); mesosinusid open (19) or closed (3); mesolophid reaching the border of the molar (15) or ends in a mesostylid (6); ectomesolophid absent; hypolophulid anterior transverse (17) or transverse (5); hypoconid hind arm absent; posterolophid continuous (18) or interrupted (1); labial posterolophid absent (17) or small (2).

m2-labial anterolophid present; metalophulid absent (1), anterior complete (38), or connected to the anteroconid (2); protoconid hind arm absent (6), short free (6), transverse and low connected to the 


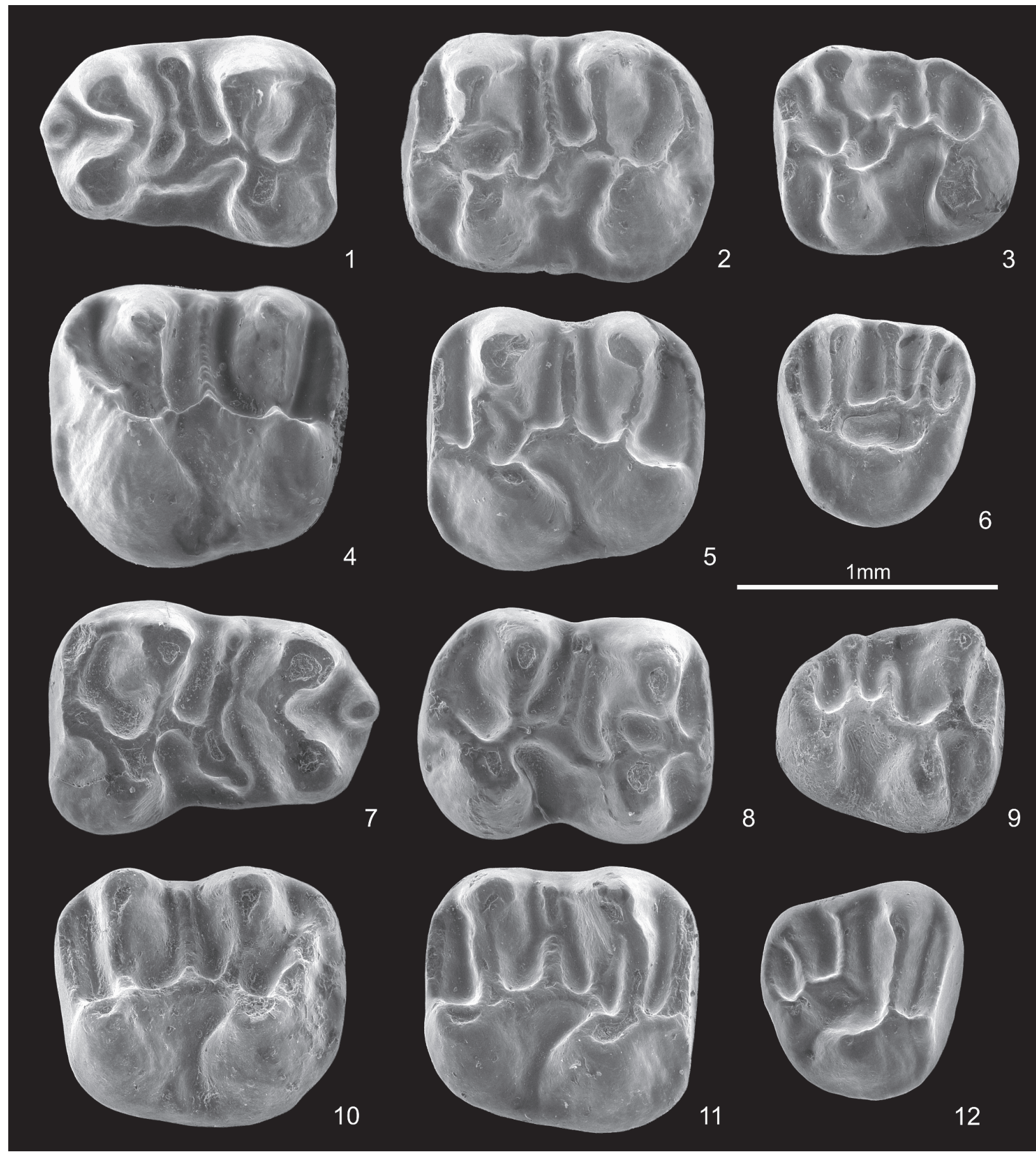

FIGURE 3. Plesiosminthus margaritae $\mathrm{n}$. sp. from Mirambueno 1 (occlusal views). 1, m1 sin., RGM 558099; 2, m2 sin., MIR1 168; 3, m3 sin., RGM 558149; 4, M1 sin., RGM 558200; 5, M2 sin., MIR1 189; 6, M3 sin., MIR1 196; 7, m1 dext., RGM 558105; 8, m2 dext., RGM 558138; 9, m3 dext., MIR1 178; 10, M1 dext., MIR1 187; 11, M2 dext., MIR1 193 (Holotype); and 12, M3 dext., MIR1 197.

metaconid (20), transverse and high connected to the metaconid (2), medium-length and free (5), bent and low connected to the metaconid (2), or bent and high connected to the metaconid (1); ectolophid longitudinal (13) or oblique (29); ectolophid complete (41) or anteriorly interrupted (1); mesoconid absent
(32) or weak (8); mesosinusid open (37) or closed (4); mesolophid reaching the border of the molar (37) or ends in a mesostylid (5); ectomesolophid absent; hypolophulid anterior transverse (41) or transverse (1); hypoconid hind arm absent (39) or 

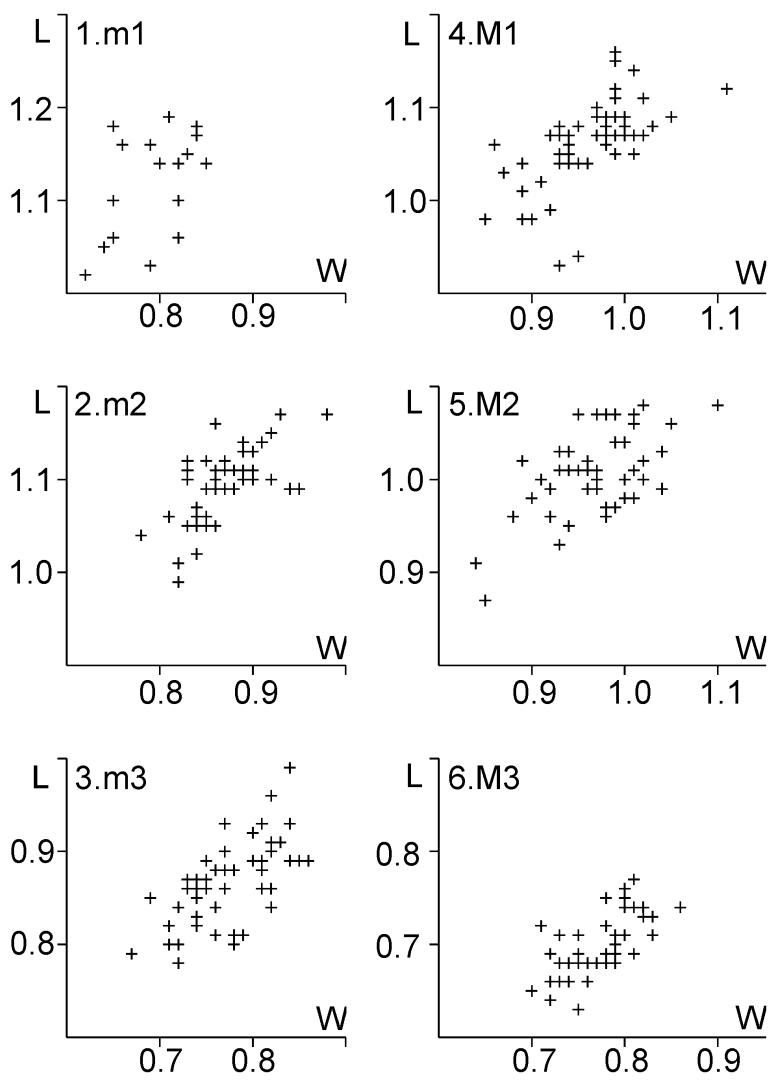

FIGURE 4. Scatter diagrams of molar length $(L)$ and width (W) of Plesiosminthus margaritae n. sp. from Mirambueno 1 (in mm). 1, m1; 2, m2; 3, m3; 4, M1; 5, $\mathrm{M} 2$; and 6, M3.

short (2); posterolophid continuous; labial posterolophid absent (29), small (7), or strong (2).

m3-lingual anterolophid absent (2), short (2), or long (39); labial anterolophid long; metalophulid absent (5), connected to the anteroconid (8), to anterolophulid (23), to protoconid (4), or double (3); protoconid hind arm absent (28), short free (5), transverse and low connected to the metaconid (9), or long and ending free (1); sinusid open; sinusid narrow transverse (7), broad transverse (1), narrow backwards (32), or broad backwards (3); mesosinusid open (13) or closed (29); mesolophid absent (2), short (1), of medium length (5), long (22), reaching the border of the molar (11), or ends in a mesostylid (2); ectomesolophid absent; entoconid absent (13), small (24), or large (4); hypolophulid anterior oblique (7) or anterior transverse (35); hypoconid hind arm absent; posterosinusid open (4), half closed (17), or closed (21); shape short triangle (11), long triangle (7), or trapezoid (23); in four specimens there is a longitudinal connection metaconidmesoconid.
M1-anterocone absent (46) or present (4); anterostyle absent (43) or present (5); anterolophule continuous; antecingulum absent (44) or present (10); protolophule double (1) or posterior (53); sinus open (51), half closed (1), or there is an entostyle (1); sinus strong forward (3), forward (50), or transverse (1); mesosinus open; mesoloph reaching the border of the molar (52) or connected to a mesostyle (1); entomesoloph absent (52) or short (2); metalophule anterior (6) or transverse (48); posterosinus large and open (44), small and open (6), or small and closed (1).

M2-lingual anteroloph absent (11), weak (17), or strong (11); protolophule anterior (10), anterior plus incomplete posterior connection (16), transverse (2), or double (15); sinus open (41) or there is an entostyle (2); sinus strong forward (6) or forward (37); mesosinus open (40) or closed (1); mesoloph reaching the border of the molar, no mesostyle. Entoloph-protocone connection high (6), low (23), or interrupted (13); metalophule anterior (27) or transverse (15); posterosinus large and open.

M3-lingual anteroloph absent (25) or weak (9); protocone is a distinct cusp (17) or a mere crest (17); protolophule absent (2), to anterocone (9), to anterolophule (14), transverse to axioloph (8), or double (1); sinus absent (15), very small (8), small (5), or deep (7); neo-entoloph absent (2), interrupted (5), low (4), or high (24); mesosinus open (30) or closed (3); mesoloph reaching the border of the molar (26) or connected to a mesostyle (7); old entoloph absent (10), curved spur (1), or complete (24); axioloph absent (2), short posterior spur (1), long posterior spur (7), or = old entoloph (25); centroloph absent; centrocone absent (31), present (1), or on old entoloph (2); metacone absent (18) or present (16); posterosinus open (3) or closed (32).

Plesiosminthus margaritae $\mathrm{n}$. $\mathrm{sp}$. differs from $P$. moniqueae n. sp. by: the better developed posterior protolophule in $\mathrm{M} 2$, the general absence of anterocone and anterostyle in $\mathrm{M} 1$ and of the mesostyle in M1 and M2; the frequent absence of a protoconid hind arm in m3. Plesiosminthus margaritae n. sp. differs from $P$. bavaricus by: on average shorter molars; protoconid hind arm of $\mathrm{m} 1$ bent in less than half the cases $(41 \%$ vs. $91 \%)$; the rare presence of an ectostylid/cingulum in $\mathrm{m} 1$; the on average shorter mesolophid in $\mathrm{m} 3$; the more frequently complete posterior protolophule in $\mathrm{M} 2$, the less frequently interrupted entoloph-protocone connection in M2 (31\% vs. $100 \%)$.

N.B. The two smallest M2 from MIR1 (RGM $5582610.91 \mathrm{~mm}$ x $0.84 \mathrm{~mm}$; RGM 5582640.87 $\mathrm{mm} \times 0.85 \mathrm{~mm}$ ) may belong to a different species. The distribution in Figure 4 appears to be discontinuous. 

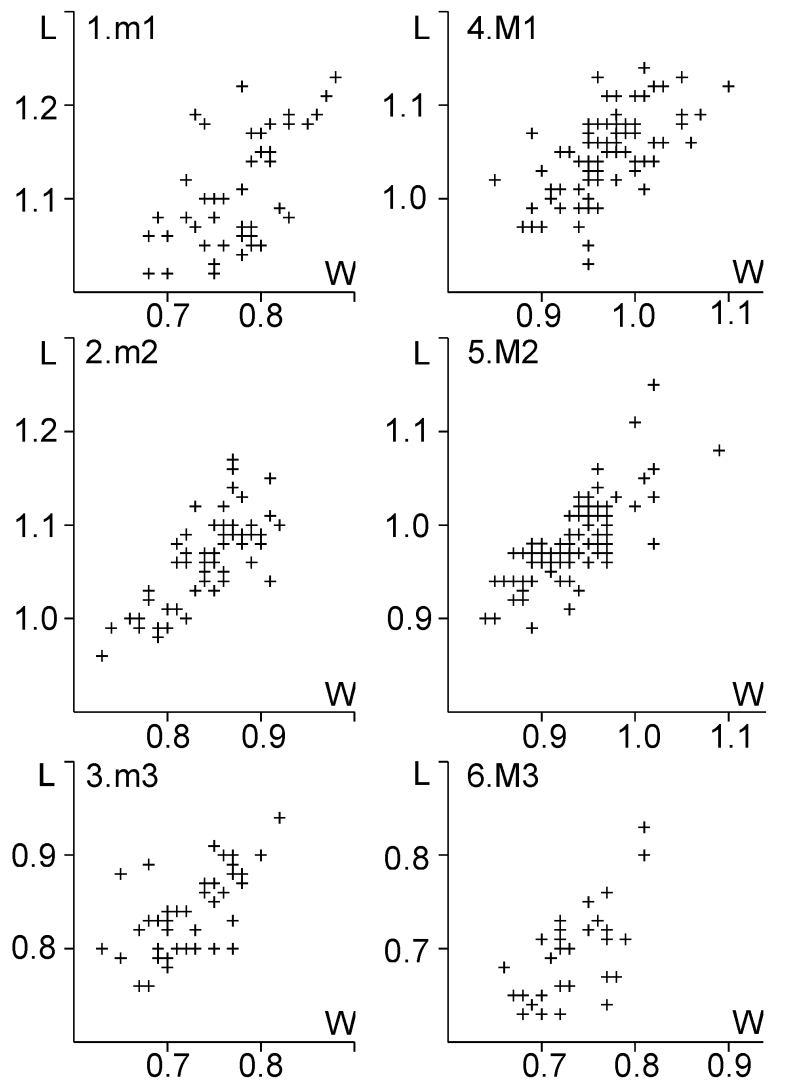

FIGURE 5. Scatter diagrams of molar length $(L)$ and width (W) of Plesiosminthus cf. margaritae $\mathrm{n}$. sp. from Vivel del Río 1 (in mm). 1, m1; 2, m2; 3, m3; 4, M1; 5, M2; and 6, M3.

\section{Plesiosminthus cf. margaritae n. sp.}

Locality. Vivel del Río 1, MP28, Spain.

Material. Collection Naturalis-Leiden: 40 m1, RGM 558308-558347; $31 \mathrm{~m} 2$, RGM 558348-558378; 38 m3, RGM 558379-558416; 7 P4, RGM 558525558531; 40 M1, RGM 558417-558456; 47 M2, RGM 558457-558503; 21 M3, RGM 558504558524. Collection Zaragoza: $10 \mathrm{~m} 1$, VIV 514523; 23 m2, VIV 524-546; 3 m3, VIV 547-549; 31 M1, VIV 550-580; 29 M2, VIV 581-609; 10 M3, VIV 610-619.

Measurements. Appendix 1, Figure 5. Description. Number of specimens in brackets.

m1-anteroconid absent (3), small (33), or with cingulum (7); anterolophulid absent (42) or present (2); metalophulid absent; protoconid hind arm absent (1), transverse and low connected to the metaconid (8), transverse and high connected to the metaconid (20), bent and low connected to the metaconid (6), or bent and high connected to the metaconid (9); ectolophid longitudinal (3) or oblique (46); ectolophid complete (32) or anteriorly interrupted (17); mesoconid absent (12), weak (25), or strong (11); mesosinusid open (44) or closed (5); mesolophid reaching the border of the molar (37) or ending in a mesostylid (13), ectomesolophid absent; hypolophulid anterior oblique (1), anterior transverse (41), or transverse (7), hypoconid hind arm absent (45) or short (1); posterolophid continuous (36) or low connected (4); labial posterolophid absent (27), small (7), or strong (14); in five specimens there is a longitudinal connection metaconid-mesoconid; seven specimens have hypoconulid.

$\mathrm{m} 2$-labial anterolophid present; metalophulid anterior interrupted (2), anterior complete (40), or connected to the anteroconid (10); protoconid hind arm absent (27), short free (8), transverse and low connected to the metaconid (14), transverse and high connected to the metaconid (1), or bent and low connected to the metaconid (1); ectolophid longitudinal (20), oblique (29), or curved (3); ectolophid complete (51) or anteriorly interrupted (1); mesoconid absent (41), weak (8), or strong (1); mesosinusid open (46) or closed (6); mesolophid long (2), reaching the border of the molar (46), or ending in a mesostylid (4); ectomesolophid absent (51) or weak (1); hypolophulid anterior oblique (1) or anterior transverse (51); hypoconid hind arm absent; posterolophid continuous; labial posterolophid absent (42), small (5), or strong (4); in five specimens there is a longitudinal connection metaconid-mesoconid; one specimen has a hypoconulid.

m3 - lingual anterolophid absent (1), short (2), or long (37); labial anterolophid long; metalophulid absent (1), anterior interrupted (3), connected to the anteroconid (3) or to anterolophulid (32); protoconid hind arm absent (37) or transverse and low connected to the metaconid (2); sinusid open; sinusid narrow backwards (3) or broad backwards (36); mesosinusid open (4) or closed (34); mesolophid of medium length (12), long (21), or reaching the border of the molar (6); ectomesolophid absent; entoconid absent (10), small (17), or large (8); hypolophulid anterior oblique (1), anterior transverse (33), or transverse (1); hypoconid hind arm absent; posterosinusid open (2), half closed (2), or closed (33); shape short triangle (10), long triangle (17), or trapezoid (12); in two specimens there is a longitudinal connection hypolophulid-mesoconid.

M1 - anterocone absent (59) or present (9); anterostyle absent; anterolophule continuous; antecingulum absent (40) or present (29); protolophule transverse (1), double (1), posterior interrupted (1), or posterior (68); sinus open (68), closed (1), or there is an entostyle (1); sinus forward (70) or transverse (1); mesosinus open (70) or closed (1); mesoloph of medium length (1), reaching the border of the molar (61), or connected to a mesostyle (9); entomesoloph absent (70) or short (1); metalophule anterior (31), transverse (39), or curved backward (1); posterosinus large and open (67) or large and closed (1). 
M2 - lingual anteroloph absent (21), weak (41), or strong (9); protolophule anterior (27), anterior plus incomplete posterior connection (3), transverse (12), or double (27); sinus open (71) or there is an entostyle (2); sinus strong forward (9) or forward (64); mesosinus open (67) or closed (6); mesoloph reaching the border of the molar (71) or connected to a mesostyle (3); entoloph-protocone connection high (2), low (32), or interrupted (34); metalophule anterior (35) or transverse (36); posterosinus large and open (59) or large and closed (11).

M3 - lingual anteroloph absent (20), weak (3), or strong (2); protocone a distinct cusp (18) or a mere crest (8); protolophule to anterocone (11), to anterolophule (18), or transverse to axioloph (1); sinus absent (2), very small (2), small (15), or deep (10); neo-entoloph absent (3), interrupted (9), low (6), or high (8); mesosinus open (23) or closed (6); mesoloph reaching the border of the molar (26) or connected to a mesostyle (4); old entoloph absent (12), curved spur (1), long spur (1), or complete (16); axioloph absent (2), short posterior spur (2), long posterior spur (8), complete (1), or = old entoloph (17); centroloph absent; centrocone absent (29) or on old entoloph (1); metacone absent (17) or present (12); posterosinus open (8) or closed (21).

N.B. Hugueney et al. (1987) mentioned P. promyarion from VIV1, but did not describe it. We provisionally call it $P$. cf. margaritae $\mathrm{n}$. sp. in order to avoid creating yet another species, but there are important differences with the type material: whereas the MV value of $\mathrm{m} 2$ is higher in VIV1 $(0.610$ vs. 0.270$)$, the value for $M 2$ is lower $(0.410$ vs. 0.535) than in P. margaritae n. sp. from the type locality. Other differences are: The pcdha of $\mathrm{m} 3$ is nearly always absent in VIV1; the sinusid of $\mathrm{m} 3$ is wider in VIV1; the antecingulum of M1 is more frequent in VIV1; the neo-entoloph of M3 is less developed in VIV1.

Plesiosminthus conjunctus Ziegler, 1994

Type locality. Herrlingen 8, MP28, Germany. Holotype. Mandible with $\mathrm{m} 1-\mathrm{m} 3$, Staatliches Museum für Naturkunde Stuttgart, SMNS 45661.

Material and measurements. Appendix 1.

Diagnosis. Translated from Ziegler (1994); Plesiosminthus of medium size. Protoconid hind arm of $\mathrm{m} 2$ predominantly connected to the metaconid.

Plesiosminthus aff. conjunctus Ziegler, 1994

Locality. Mirambueno 2A, MP27, Spain.

Material. Collection Naturalis-Leiden: 16 m1, RGM 558532-558547; 14 m2, RGM 558548-558561; 15 m3, RGM 558562-558567, 558569-558577; 2 P4, RGM 558632-558633; 27 M1, RGM 558578558604; 19 M2, RGM 558605-558623; 8 M3, RGM 558624-558631. Collection Zaragoza: 3 m1,
MIR2A 82-84; 5 m2, MIR2A 85-89; 5 m3, MIR2A 90-94; 6 M1, MIR2A 95-100; 9 M2, MIR2A 101109; 8 M3, MIR2A 111-118.

Measurements. Appendix 1, Figure 6.

Description. Number of specimens in brackets.

m1-anteroconid absent (1), small (15), or with cingulum (2); anterolophulid absent (17) or present (1); metalophulid absent; protoconid hind arm transverse and high connected to the metaconid (18) or bent and high connected to the metaconid (1); ectolophid oblique; ectolophid complete (13), anteriorly interrupted (4), posteriorly interrupted (1), or isolated (1); mesoconid absent (9), weak (8), or strong (1); mesosinusid open (18) or closed (1); mesolophid reaches the border of the molar (11) or ends in a mesostylid (8); ectomesolophid absent; hypolophulid anterior oblique (1), anterior transverse (17), or transverse (1); hypoconid hind arm absent (15) or short (1); posterolophid continuous (14) or low connected (2); labial posterolophid absent (15) or small (2); in one specimen, there is a longitudinal connection metaconid-mesoconid.

m2-labial anterolophid present; metalophulid anterior complete (14) or connected to the anteroconid (4); protoconid hind arm absent (3), transverse and low connected to the metaconid (14), or bent and low connected to the metaconid (1); ectolophid longitudinal (11) or oblique (7); ectolophid complete (17) or anteriorly interrupted (1); mesoconid absent (12), weak (4), or strong (2); mesosinusid open (13) or closed (4); mesolophid reaches the border of the molar (16) or ends in a mesostylid (1); ectomesolophid absent (17) or weak (1); hypolophulid anterior oblique (2) or anterior transverse (16); hypoconid hind arm absent; posterolophid continuous (14) or low connected (1); labial posterolophid absent (12) or small (4); In one specimen, there is a longitudinal connection metaconid-mesoconid.

m3-lingual anterolophid long; labial anterolophid long; metalophulid absent (1), connected to the anteroconid (12), to anterolophulid (5), or to protoconid (2); protoconid hind arm absent (13), short and free (3), transverse and low connected to the metaconid (3), or long and ending free (1); sinusid open; sinusid narrow backwards (4) or broad backwards (16); mesosinusid open (3) or closed (16); mesolophid absent (1), of medium length (2), long (10), or reaching the border of the molar (6); ectomesolophid absent; entoconid absent (11), small (4), or large (2); hypolophulid anterior oblique (3) or anterior transverse (15); hypoconid hind arm absent; posterosinusid half closed (1) or closed (18); shape short triangle (5), long triangle (6), or trapezoid (8); in four specimens there is a longitudinal connection metaconid-mesoconid.

M1-anterocone absent; anterostyle absent; anterolophule continuous (31) or interrupted (1); antecingulum absent (11) or present (20); protol- 

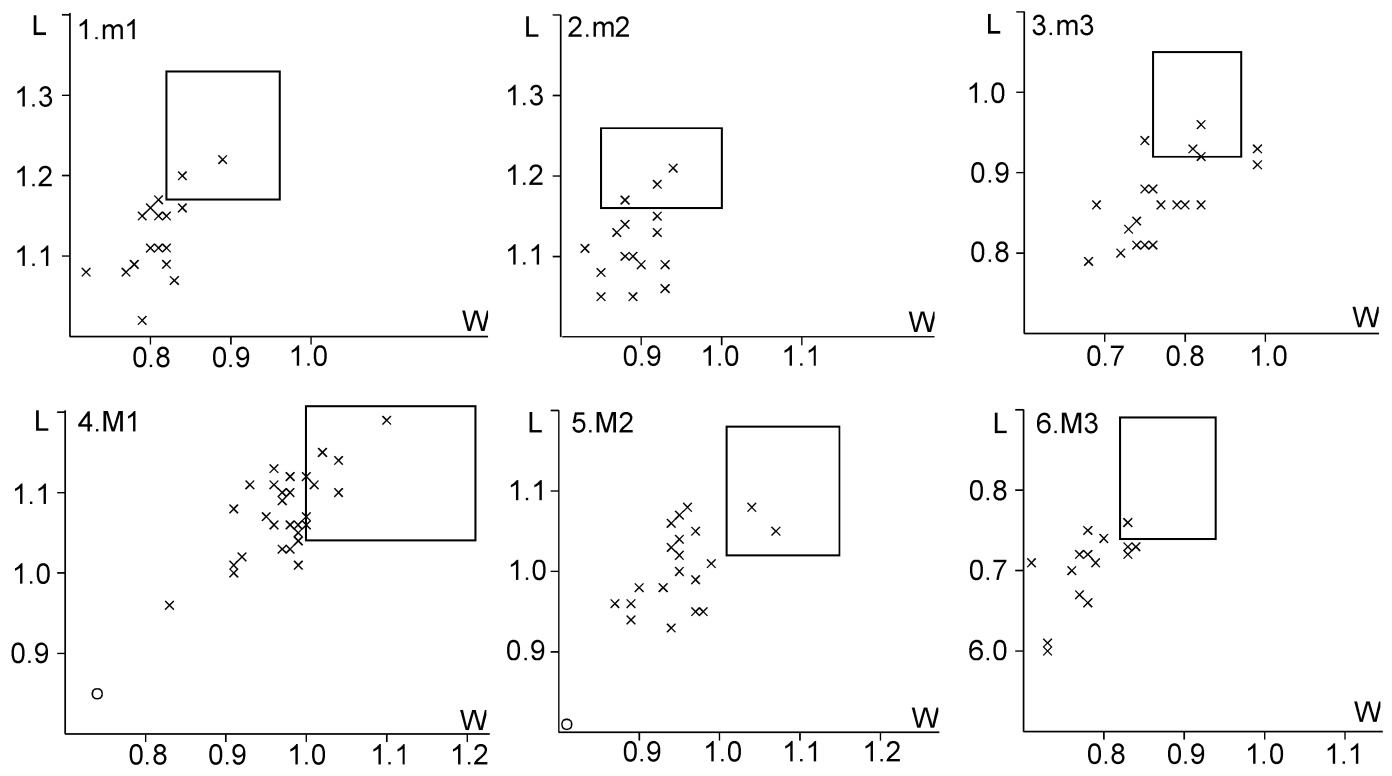

FIGURE 6. Scatter diagrams of molar length (L) and width (W) of Plesiosminthus aff. conjunctus (cross) and Plesiosminthus sp. (circle) from Mirambueno 2A, compared with the distribution area (rectangle) of Plesiosminthus conjunctus molars from HERR8 (in mm). 1, m1; 2, m2; 3, m3; 4, M1; 5, M2; and 6, M3.

ophule posterior plus a trace of an anterior connection (1) or posterior (32); sinus open (30) or there is an entostyle (2); sinus forward; mesosinus open; mesoloph reaching the border of the molar; entomesoloph absent; metalophule anterior (15) or transverse (18); posterosinus large and open (28), large and closed (1), or small and open (1).

M2-lingual anteroloph absent (10), weak (7), or strong (9); protolophule anterior (1), anterior plus incomplete posterior connection (2), transverse (4), or double (20); sinus open (27) or there is an entostyle (1); sinus strong forward (1) or forward (27); mesosinus open (15) or closed (10); mesoloph of medium length (1) or reaching the border of the molar (25), no mesostyle; entoloph-protocone connection high (3), low (17), or interrupted (5); metalophule anterior (13) or transverse (11);posterosinus large and open (17) or large closed (7).

M3-lingual anteroloph absent (14) or weak (1); protocone a distinct cusp (8) or a mere crest (7); protolophule to anterolophule; sinus absent (3), very small (6), small (4), or deep (2); neo-entoloph absent (2), low (2), or high (10); mesosinus open (6) or closed (9); mesoloph reaches the border of the molar (14) or connected to a mesostyle (2); old entoloph absent (9), curved spur (1), or complete (6); axioloph absent (2), short posterior spur (1), long posterior spur (6), complete (1), or = old entoloph (6); centroloph absent; centrocone absent (15) or isolated (1); metacone absent (5) or present (9); posterosinus open (1) or closed (12).

Plesiosminthus conjunctus from Herrlingen 8 is characterized by the primitive state of the pcdha of $\mathrm{m} 2$ (82\% complete, never absent), combined with an advanced state of the protolophule of M2 (75\% double). For an evaluation of "primitive" and "advanced" see the section on morphology values. These values are similar to those found in MIR2A (see Table 3). However, $P$. conjunctus from HERR8 is clearly larger than $P$. aff. conjunctus from MIR2A (see Figures 7-12). Other differences are: The protoconid hind arm of $\mathrm{m} 3$ is always absent in HERR8, and present, complete, or incomplete, in $35 \%$ of the specimens in MIR2A; the mesostylid is better developed in the m1, 2 from HERR8; the entoloph-protocone connection of $\mathrm{M} 2$ is more frequently interrupted in HERR8.

Plesiosminthus schaubi Viret, 1926

Type locality. Coderet, MP30, France.

Holotype. Mandibula sin. with m1-m3, nr. 96325, coll. Lyon.

Material and measurements. Appendix 1.

Diagnosis. Combined from Hugueney (1969) and Hugueney and Vianey-Liaud (1980). Anteroconid of $\mathrm{m} 1$ clearly separated from protoconid, generally connected to the metaconid; protoconid hind arm straight or little curved; ectolophid incomplete; no protoconid hind arm in $\mathrm{m} 2$; the $\mathrm{m} 3$ has a maximum of four lingual crests; P4 with big root and crown of little importance; M3 and m3 with simplified posterior lobe; crown of M1 broad; protolophule posterior in M1, anterior in M2 and M3; M2 with simple anterior protolophule. 


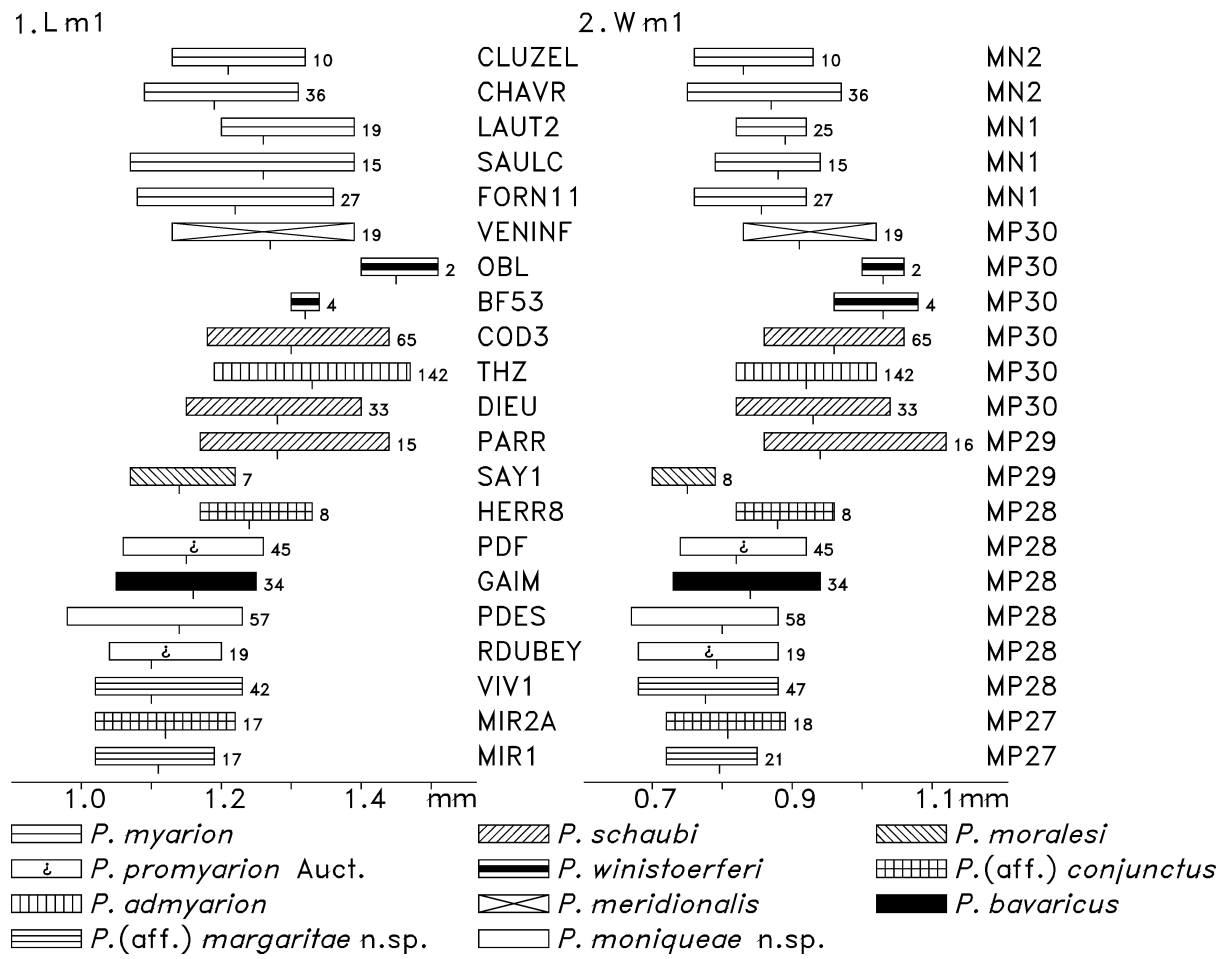

FIGURE 7. $\mathrm{m} 1$ length (1) and width (2) of Plesiosminthus species. The bars represent the minimum and maximum in $\mathrm{mm}$, a tick marks the mean, and the number of specimens is given to the right.

Plesiosminthus admyarion Comte, 2000

Type locality. Thézels, MP30, France.

Holotype. m2 dext., Th. 7582, coll. University Poitiers.

Material and measurements. See Appendix 1.

Diagnosis. Translated from Comte (2000). Dimensions similar to those of the type material of $P$. schaubi, and sharing a number of morphological features with that species, but the relative proportions of the teeth and several other characters show affinities with $P$. myarion.

According to its author, $P$. admyarion Comte, 2000 is significantly different from $P$. schaubi from Coderet in terms of size: its $\mathrm{m} 1, \mathrm{~m} 3$, and $\mathrm{M} 3$ are significantly longer, its $M 1, M 2$, and $m 2$ are significantly shorter. The t-test values reported by Comte are somewhat different from our results (see Table 4) because that author applied the formula for equal variances (Vianey-Liaud, personal commun., 2016), but we confirm the differences are significant at $\alpha=0.05$. However, the distributions of the measurements (Figures 7-12) largely overlap and size can hardly serve to distinguish these species.

The MV values are very similar: very high values for $\mathrm{m} 2$ and the lowest values of all species for M2. Plesiosminthus admyarion and P. schaubi are probably closely related. Among the differences is the more reduced $\mathrm{m} 3$ of $P$. schaubi (maximum four lingual crests). Another difference is found in the anteroconid of $m 1$ : isolated $(n=39)$, connected to the metaconid (30), or to the protoconid (39); in Coderet it is rarely isolated, generally connected to the metaconid, never to the protoconid.

Plesiosminthus meridionalis Comte, 2000

Type locality. Venelles inf., MP30, France.

Holotype. m1 dext., VEL. 420, coll. University Montpellier II.

Material and measurements. Appendix 1.

Diagnosis. Translated from Comte (2000). Differs from Plesiosminthus schaubi by the shorter mesolophid, not connected to the mesostylid in the lower molars.

According to the description by Comte the mesolophid is separated from the mesostylid in $40 \%$ of the $m 1(n=20)$ and $77 \%$ of the $m 2(n=$ 26). Plesiosminthus meridionalis, originally described as a subspecies of $P$. schaubi, and here treated as a species, is characterized by the very high MV values of both $\mathrm{m} 2$ and M2 (see Figure 2, Tables 3,5$)$. In this respect it is the most advanced species, very different from $P$. schaubi, and a close relationship is not probable. 


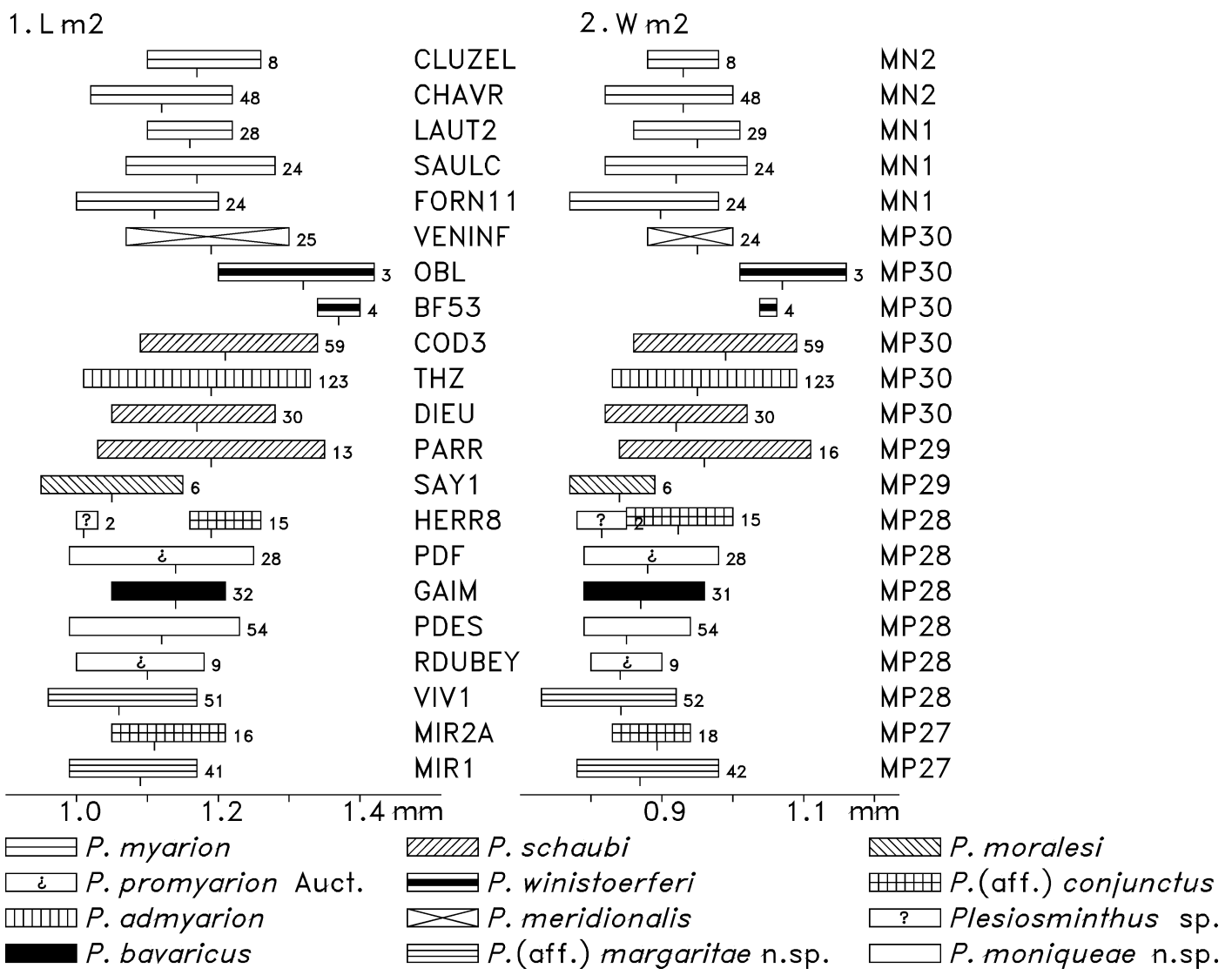

FIGURE 8. $\mathrm{m} 2$ length (1) and width (2) of Plesiosminthus species. The bars represent the minimum and maximum in $\mathrm{mm}$, a tick marks the mean, and the number of specimens is given to the right.

Plesiosminthus moralesi Alvarez Sierra, Daams and Lacomba Andueza, 1996

Type locality. Sayatón 1, MP29, Spain. Holotype. M1 sin., SAY1 108, Department of Paleontology, Universidad Complutense Madrid.

Material and measurements. Appendix 1.

Original diagnosis. Small Plesiosminthus species with a well-developed antero-lingual cingulum ridge in $\mathrm{M} 1,2$, with a continuous anteroloph in $\mathrm{M} 1$ in which traces of an anteroconule are absent, and with a relatively short mesolophid in the lower molars.

Plesiosminthus myarion Schaub, 1930

Type locality. Chavroches, MN2, France.

Syntypes. Two maxillas and two mandibles figured by Schaub (1930, figures 5-9).

Material and measurements. Appendix 1.

Diagnosis. Adapted from Schaub (1930). Lamella of the canalis nervi infraorbitalis reaching the anterior border of the foramen foramen infraorbitale; anterior end of the upper toothrow farther away from the jugal arch than in Plesiosminthus schaubi;
P4 smaller, with thinner root and clearly set-off crown; M3 and $\mathrm{m} 3$ with reduced but complete posterior lobe; M1 narrow, with new (posterior) protolophule; M2 almost as large as M1, with double protolophule, M3 small, with old (anterior) protolophule; anteroconid of $\mathrm{m} 1$ connected to the protoconid; ectolophid well developed: protoconid hind arm frequent in $\mathrm{m} 2$, rare in $\mathrm{m} 3$.

Plesiosminthus winistoerferi Engesser, 1987

Type locality. Brochene Fluh 53, MP30, Switzerland.

Holotype. m2 sin., Br.F. 1, Naturhistorisches Museum Basel.

Material and measurements. Appendix 1.

Diagnosis. From Engesser (1987). "Very large species of Plesiosminthus with very long and strong posterior arm of protoconid on $\mathrm{m} 2$ and $\mathrm{m} 3$, double protoloph on $\mathrm{M} 2$ and $\mathrm{M} 3$, and little reduced $m 3 / M 3$. $m 1$ always with secondary ridge between metalophid and mesolophid. Entoloph of M2 situated far lingually, ectolophid of $\mathrm{m} 2$ and $\mathrm{m} 3$ far labially. Connection between protoconid and anterior cingulum of $\mathrm{m} 2$ and $\mathrm{m} 3$ sometimes interrupted. $\mathrm{m} 2$ 
FREUdENTHAL \& MARTín-SuÁREZ: EuROPEAN PLESIOSMINTHUS

1. $L \mathrm{~m} 3$

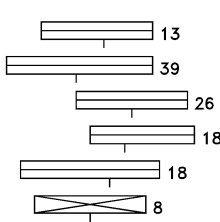

एवायाएगया 32

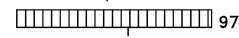
एIIIIIIIII 20

$\mathbb{\$}$

$$
\text { EIIIIA } 2
$$
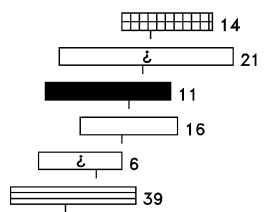

册册冊 20

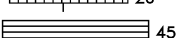

2. W m3

\begin{tabular}{|c|c|c|}
\hline CLUZEL & $\rightleftharpoons_{13}$ & MN2 \\
\hline CHAVR & $\underbrace{}_{39}$ & MN2 \\
\hline LAUT2 & $\rightleftharpoons_{26}$ & MN1 \\
\hline SAULC & $\mathrm{F}_{18}$ & MN1 \\
\hline FORN11 & 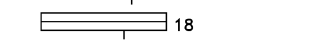 & MN1 \\
\hline VENINF & $\sum_{8}^{1}$ & MP30 \\
\hline OBL & $\nabla_{2}$ & MP30 \\
\hline BF53 & & MP30 \\
\hline coD3 & 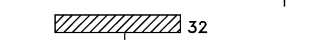 & MP30 \\
\hline THZ & एسणm & MP30 \\
\hline DIEU & सIIIIII 20 & MP30 \\
\hline PARR & IIय 3 & MP29 \\
\hline SAY 1 & $\mathbb{Q}_{1}$ & MP29 \\
\hline HERR8 & 曲册曲 14 & MP28 \\
\hline PDF & $\frac{i}{i}{ }_{21}$ & MP28 \\
\hline GAIM & $P_{11}$ & MP28 \\
\hline PDES & ${ }^{\prime}{ }_{14}$ & MP28 \\
\hline RDUBEY & $i$ & MP28 \\
\hline VIV1 & 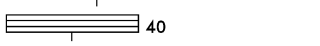 & MP28 \\
\hline MIR2A & 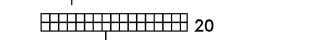 & MP27 \\
\hline MIR1 & 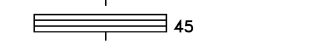 & MP27 \\
\hline
\end{tabular}

$$
1.3 \mathrm{~mm}
$$

एIII] P. schaubi

Wher P. moralesi

巴两田P. (aff.) conjunctus

$P$. bavaricus

$\begin{array}{ll}\mathrm{m} \mathrm{m} \text { P. admyarion } & \square \text { P. meridionalis } \\ \equiv \text { P. (aff.) margaritae n.sp. } & \square \text { P. moniqueae n.sp. }\end{array}$

FIGURE 9. m3 length (1) and width (2) of Plesiosminthus species. The bars represent the minimum and maximum in $\mathrm{mm}$, a tick marks the mean, and the number of specimens is given to the right.

1. $L M 1$

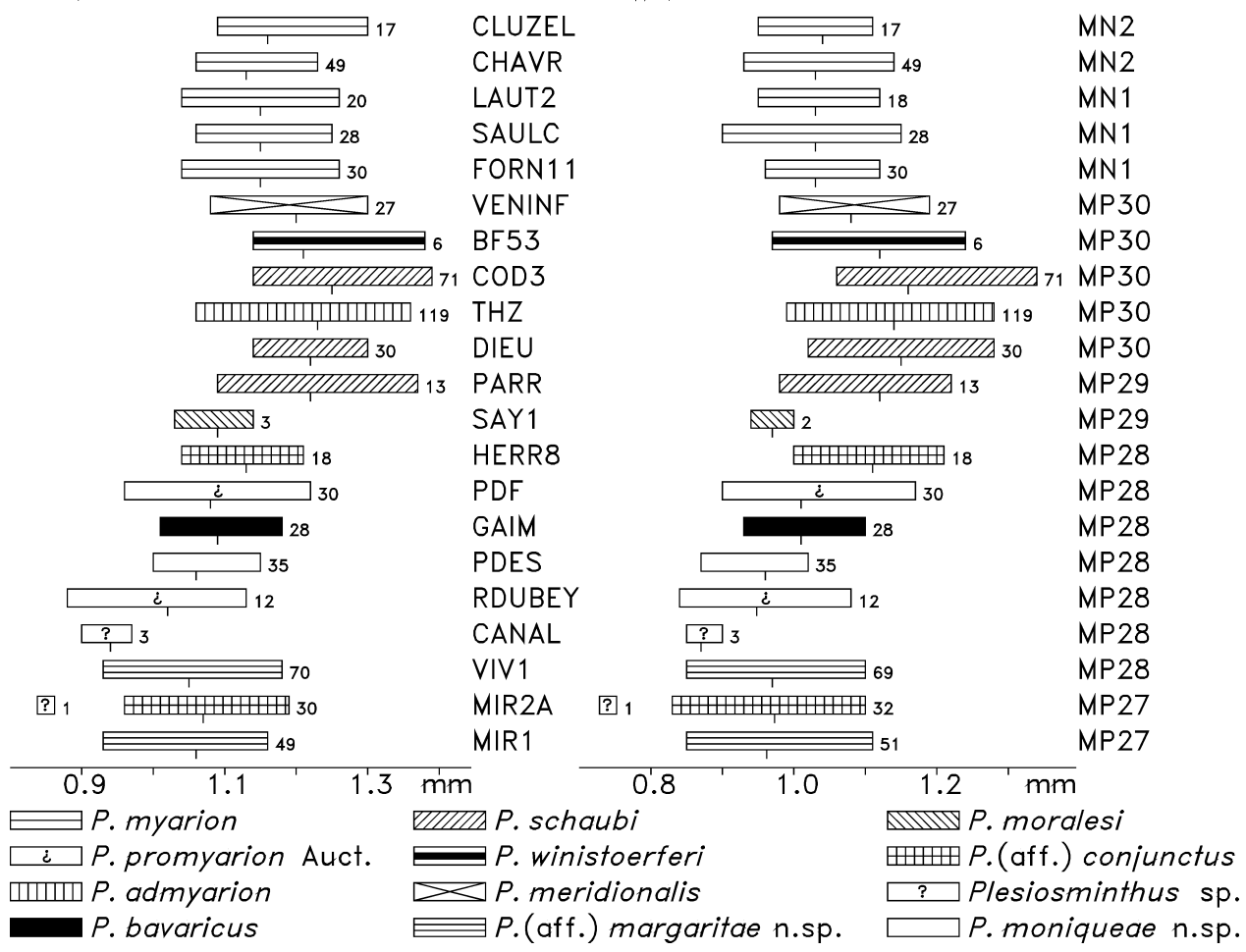

FIGURE 10. M1 length (1) and width (2) of Plesiosminthus species. The bars represent the minimum and maximum in $\mathrm{mm}$, a tick marks the mean, and the number of specimens is given to the right. 
1. LM2

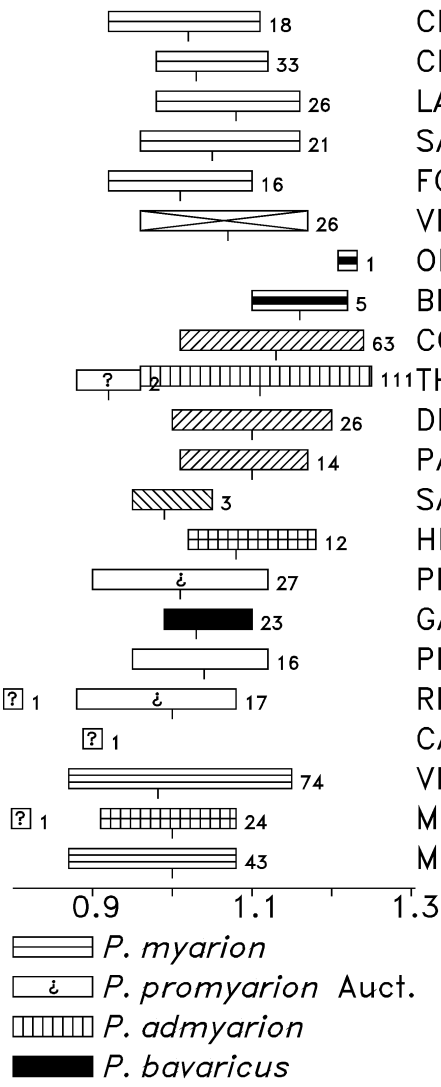

2. WM2

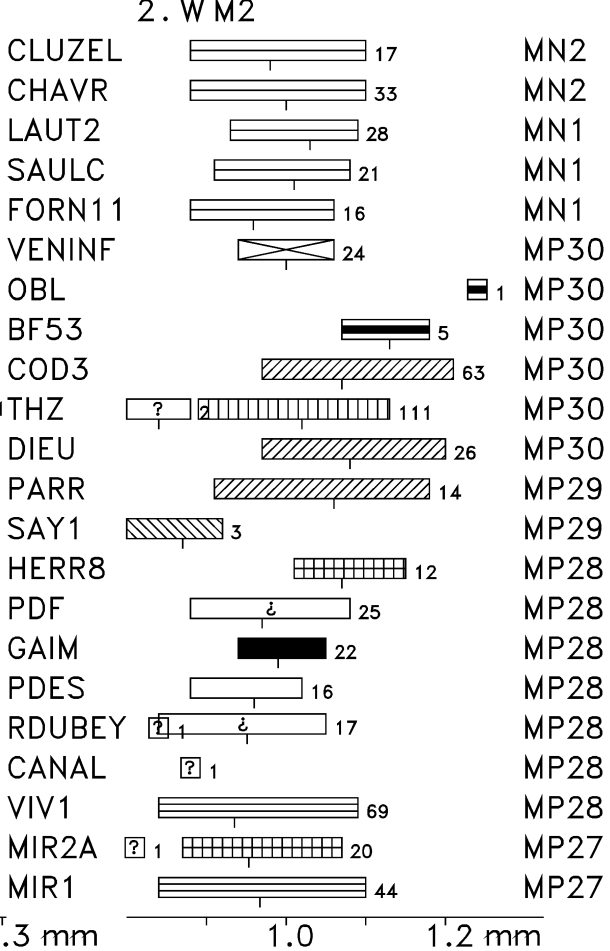

घIIIIA P. schaubi

P. winistoerferi

$\bowtie$ P. meridionalis

$\rightleftharpoons P$.(aff.) margaritae n.sp.
MIIU P. moralesi

册册P. (aff.) conjunctus

? Plesiosminthus sp.

$\square$ P. moniqueae n.sp.

FIGURE 11. M2 length (1) and width (2) of Plesiosminthus species. The bars represent the minimum and maximum in $\mathrm{mm}$, a tick marks the mean, and the number of specimens is given to the right.

equally wide as $\mathrm{m} 1$, but somewhat longer. Upper molars with 3 roots. Upper incisor with longitudinal groove."

It is generally assumed (Schaub, 1930; Ziegler and Werner, 1994; Engesser, 1987) that the evolutionary trend of the protoconid hind arm of Plesiosminthus is to lose contact with the metaconid, become shorter, and finally disappear. Apparently, this is not the case in $P$. winistoerferi, where the pcdha may even reach the molar border, a feature unknown in other species of the genus. It is doubtlessly the largest species known, but the length relation between $\mathrm{m} 2$ and $\mathrm{m} 1$ may be misleading due to the small number of specimens (see section "Size").

Plesiosminthus sp. small size

Apart from the species described above, a very small Plesiosminthus is documented in a number of localities:

Mirambueno 2A, MP27, Spain. M1 sup.dext., 0.85 $x$ 0.74, RGM 558568, M2 sup.dext., 0.81 x 0.81, MIR2A 110; in our material there is a clear gap between these specimens and the distribution of $P$. margaritae n. sp. (see Figure 6).

Ruisseau du Bey, MP28, Switzerland. Specimens of similar size have been reported from Ruisseau du Bey (Engesser, 1987; one M2 and maybe one M1); Engesser (1987) attributed this material to $P$. promyarion, but the size range of his sample is very large, and the small specimens probably represent another species.

Canales, MP28, Spain. The size of these specimens (three M1 and one M2) is at the lower limit of the penecontemporaneous sample from VIV1. It must, however, represent another species, because one M2 has a short mesoloph, and another one has a posterior metalophule plus an interrupted anterior connection. (see Alvarez et al. 1999).

Herrlingen 8, MP28, Germany. Two m2 from Herrlingen 8 are smaller than $P$. conjunctus from the same locality. They lack the protoconid hind arm and have a less-developed mesolophid (see Ziegler 1994). 
FREUDENTHAL \& MARTín-SUÁREZ: EUROPEAN PLESIOSMINTHUS

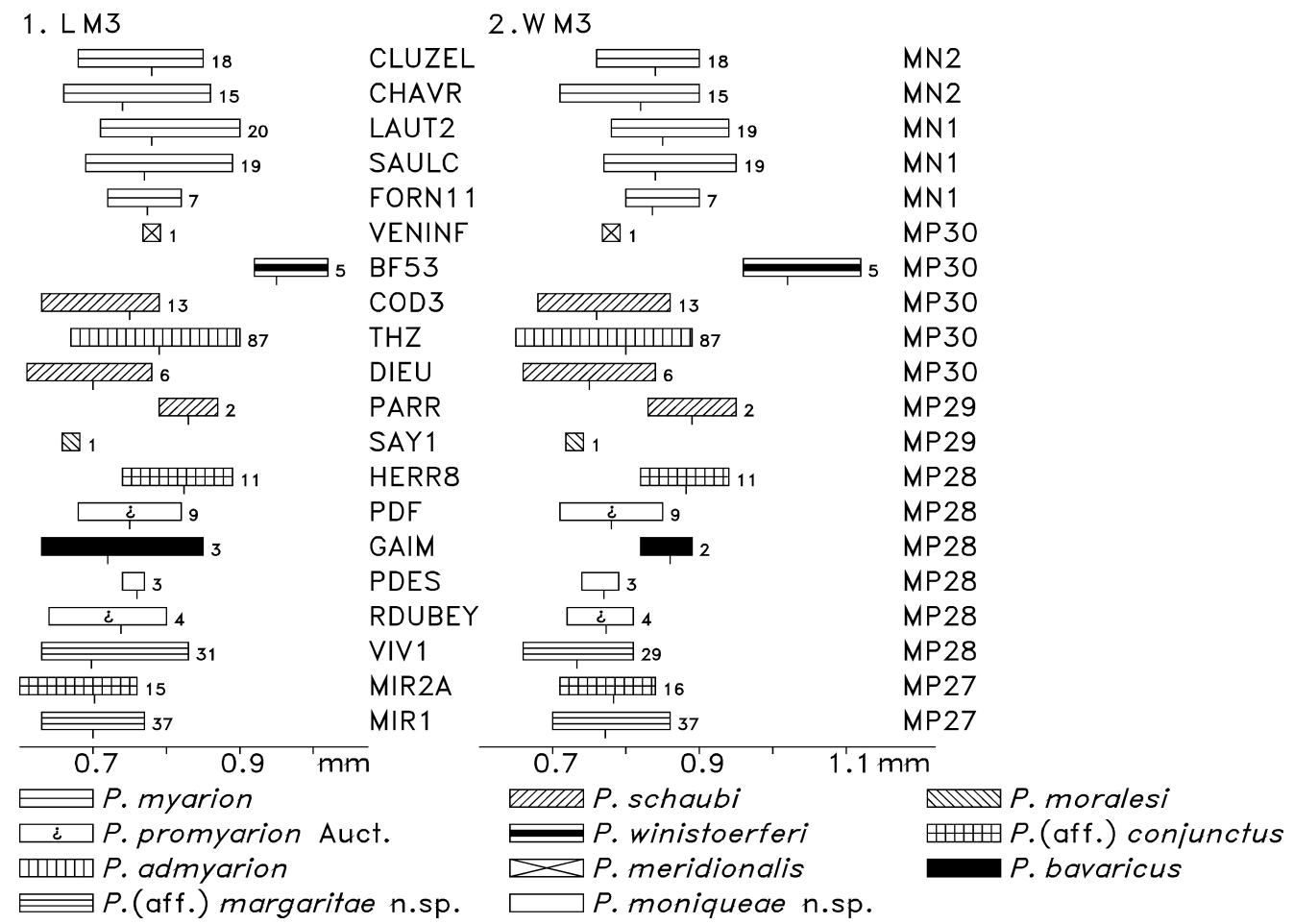

FIGURE 12. M3 length (1) and width (2) of Plesiosminthus species. The bars represent the minimum and maximum in $\mathrm{mm}$, a tick marks the mean, and the number of specimens is given to the right.

Thézels, MP30, France. Comte (2000) reported two very small $\mathrm{M} 2$ from Thézels as $P$. admyarion or Plesiosminthus sp.?.

The presence of Plesiosminthus in Mirambueno 4C and 4D (MIR4C and MIR4D), Mp26, Spain, is doubtful; no molars have been found, only several incisor fragments with the characteristic furrow. If they represent Plesiosminthus, it must be a large species. The incisors of some Gliridae present a similar furrow, but in that group the furrow is less developed (Freudenthal, 1997).

\section{MORPHOLOGY VALUES}

\section{Protolophule of M2}

Schaub (1925), in his work on Cricetidae, introduced the concept of the old and the new "Jochkanten": in the upper molars the connections from the labial cusps to the lingual ones primitvely are directed anteriorly and in the course of evolution shift posteriorly. In the lower molars a similar shift takes place, but in the opposite direction. Schaub (1930) applied this to the Dipodidae, and that has been generally accepted, (e.g., Hugueney and Vianey-Liaud, 1980; Engesser, 1987).

Like in Cricetidae, the protolophule of M2 appears to be an important diagnostic feature of the Dipodidae dentition. Following Schaub (1930), the anterior connection between protocone and paracone (protolophule I of Wood and Wilson, 1936) is considered to be the primitive situation, and a posterior connection (protolophule II) is considered to be derived. The presence of both connections is the intermediate situation. However, the presence of a posterior protolophule alone has not been observed in Plesiosminthus, except for $P$. meridionalis Comte, 2000 from Venelles inf., and, rarely, $P$. admyarion Comte, 2000 from Thézels. Kimura (2013) considered the double protolophule of $\mathrm{M} 2$ to be a primitive character, but it is best developed in P. myarion, the youngest species.

TABLE 4. P-values of t-test comparing the samples from $\mathrm{THZ}$ and COD3; $\mathrm{df}=$ degrees of freedom.

\begin{tabular}{cccc}
\hline Molar & Comte (2000) & this paper & df \\
\hline m1 & 3.18 & 3.092 & 205 \\
m2 & 2.02 & -2.162 & 180 \\
m3 & 3.00 & 2.828 & 127 \\
M1 & 2.39 & -2.483 & 188 \\
M2 & 2.06 & -2.178 & 172 \\
M3 & 3.00 & 2.832 & 98 \\
\hline
\end{tabular}


TABLE 5. Frequencies of character states of the protoconid hind arm of m2, number of observations, and morphology values. Data from Kristkoiz (1992, figure 84) and this paper.

\begin{tabular}{lccccc}
\hline Sample & complete & incomplete & absent & $\mathbf{n}$ & MV \\
\hline CHAVR & 12 & 50 & 38 & 50 & 0.630 \\
FORN11 & 26 & 52 & 22 & 27 & 0.480 \\
VENINF & 0 & 0 & 100 & 26 & 1.000 \\
COD3 & 0 & 0 & 100 & 59 & 1.000 \\
THZ & 9 & 9 & 82 & 127 & 0.865 \\
HERR8 & 82 & 18 & 0 & 17 & 0.090 \\
PDF & 36 & 53 & 11 & 28 & 0.375 \\
GAIM & 50 & 41 & 9 & 31 & 0.295 \\
PDES & 32 & 45 & 23 & 53 & 0.455 \\
RDUBEY & 31 & 69 & 0 & 13 & 0.345 \\
VIV1 & 31 & 16 & 53 & 52 & 0.610 \\
MIR2A & 83 & 0 & 17 & 16 & 0.170 \\
MIR1 & 60 & 26 & 14 & 41 & 0.270 \\
\hline
\end{tabular}

In the oldest sample (P. margaritae n. sp. from MIR1) about $35 \%$ of the M2 have a double connection, of which the anterior protolophule is stronger than the posterior one. In the youngest sample $(P$. myarion from Chavroches) there is a double connection in $97 \%$ and both crests are equally well developed. In the intermediate samples values vary, and there is no continuous trend, which probably means we are dealing with more than one evolutionary lineage. The samples from MIR1 and VIV1 are quite similar with 35 and $39 \%$ of double protolophule, respectively. The sample from MIR2A, stratigraphically between MIR1 and VIV1, has $74 \%$, much more than in the other two, and less than in Chavroches; those from MIR1 and
VIV1 may form a lineage, but MIR2A must be excluded from it.

Surprisingly, the lowest percentage is found in P. myarion from Pech Desse (12.5\%). This sample, more or less of the same age as VIV1, is the most primitive of all samples studied here with respect to the protolophule of M2. It should be noted that the number of specimens is smaller than in other samples. In Table 3 we give the morphology values for a number of samples.

\section{Protoconid Hind Arm of $\mathrm{m} 2$}

The original connection from metaconid to protoconid is supposed to be posterior; this situation is maintained in $\mathrm{m} 1$, but in $\mathrm{m} 2$ there is nearly always an anterior connection. The posterior "old"

TABLE 6. Frequencies of character states of the protoconid hind arm of $\mathrm{m} 3$, number of observations, and morphology values.

\begin{tabular}{lccccc}
\hline Sample & complete & incomplete & absent & $\mathbf{n}$ & MV \\
\hline CHAVR & 5.4 & 0.0 & 94.6 & 37 & 0.946 \\
VENINF & 0.0 & 0.0 & 100.0 & 8 & 1.000 \\
COD3 & 0.0 & 0.0 & 100.0 & 32 & 1.000 \\
THZ & 0.0 & 0.0 & 100.0 & 97 & 1.000 \\
HERR8 & 0.0 & 0.0 & 100.0 & 14 & 1.000 \\
PDF & 8.0 & 32.0 & 60.0 & 25 & 0.760 \\
GAIM & 14.9 & 27.3 & 63.6 & 11 & 0.730 \\
PDES & 25.0 & 43.8 & 31.2 & 16 & 0.531 \\
RDUBEY & 0.0 & 0.0 & 100.0 & 6 & 1.000 \\
VIV1 & 5.1 & 0.0 & 94.9 & 39 & 0.949 \\
MIR2A & 20.0 & 15.0 & 65.0 & 20 & 0.725 \\
MIR1 & 23.2 & 11.6 & 65.1 & 43 & 0.710 \\
\hline
\end{tabular}


connection may be complete, interrupted, or absent, and these character states are interpreted as consecutive evolutionary stages (Schaub, 1930; Ziegler and Werner, 1994; Engesser, 1987).

In Table 5 we give the percentages of each character state and the resulting morphology values (MV) and in Figure 2 we compare the MV of the pcdha of $\mathrm{m} 2$ with those of the protolophule of M2. As said before, $P$. meridionalis from Venelles inf. is most derived on the basis of the protolophule of $\mathrm{M} 2$, and that is confirmed by the pcdha (always absent), so that in Figure $2 \mathrm{~m} 2$ and $\mathrm{M} 2$ from Venelles both display values on the positive end of the graphs.

On the other hand, $P$. conjunctus from Herrlingen 8 and $P$. aff. conjunctus from MIR2A have very high values for the protolophule, and the lowest values for pcdha. We find this very difficult to explain. Both dental elements form part of the same functional mechanism, and one would expect parallel changes in order to make them interact correctly. Assuming a different interpretation of primitive/derived provides no solution, because then the same problem would exist for other samples. The only explanation seems to be that we are dealing with several evolutionary lineages that present fundamentally different tendencies.

In this respect, it is tempting to assume a relationship between the samples from MIR2A (MP27) and HERR8 (MP28). Plesiosminthus conjunctus from HERR8 is on average larger and has welldeveloped mesostylids, but in the development of the protolophule and pcdha both samples are identical. Ziegler (1994) suggested that $P$. schaubi from Coderet is a descendent of $P$. conjunctus. However, that hypothesis implies an abrupt leap in the morphology of the pcdha of $\mathrm{m} 2$, from $100 \%$ present to $97 \%$ absent.

Also, according to Ziegler (1994), P. conjunctus has no relation with $P$. winistoerferi from Brochene Fluh 53. That author states that $P$. winistoerferi is the most primitive species; however, it always has a double protolophule in $\mathrm{M} 2$, which we consider to be advanced. Its $\mathrm{m} 2$ has a long free ending pcdha, supposedly a primitive condition. But in this case its morphology is different from all other species, and it may be a derived situation, evolved from a relatively short pcdha, connected to the metaconid. The few available specimens do not allow a reliable conclusion.

\section{Protoconid Hind Arm of $\mathrm{m} 3$}

With respect to the pcdha, the $\mathrm{m} 3$ is constantly more advanced than $\mathrm{m} 2$. In about half the samples the pcdha is absent, and, when present, it is more reduced than in $\mathrm{m} 2$. The lowest $\mathrm{MV}$ is found in P. moniqueae n. sp. from PDES (Table 6), confirming our interpretation that it is a different species.

\section{SIZE}

In Figures 7-12 the ranges of length and width of a number of samples are represented. According to Engesser (1987), P. winistoerferi from Brochene Fluh 53 is larger than $P$. schaubi. That is true for $m 3 / M 3$, but not for the length of $m 1, M 1$, and $M 2$ and the width of $\mathrm{m} 2$; width of $\mathrm{m} 1$ and $\mathrm{M} 2$ are somewhat larger, but overlap. The number of specimens (between 4 and 6 per element) is very small and may lead to unreliable results. If its measurements are representative for a larger sample, this means that in $P$. winistoerferi the size relations between the elements are completely different from other species. We think, however, that the values for the length of $\mathrm{m} 1$ are too small. The ratio of the mean length $\mathrm{m} 1 / \mathrm{m} 2$ varies between 1.02 to 1.12 . Applying a multiplication factor of 1.06 to the length of $\mathrm{m} 2$ (mean $=1.37 \mathrm{~mm}$ ), the mean of $\mathrm{m} 1$ length should be around $1.45 \mathrm{~mm}$, a value that is indeed found in the same species from Oberleichtersbach (Engesser and Storch, 2008). Also, the few specimens from Findreuse, published by Engesser (1987), show that the type material from BF53 by no means covers the size distribution range of the species.

Using the specimen numbers given in Table 7, in Figure 13 we compare the distributions of the mean values of the length of the molars in the type samples of 10 Plesiosminthus species. In $P$. moralesi from Sayatón 1 (Alvarez et al., 1996) the $\mathrm{m} 3$ is very small, but only one specimen is available, and the mean of a larger sample would certainly be different. In most other samples the material is sufficiently abundant and the mean values are very similar. There are differences in the relation of the mean lengths of first and second molars: the ratio $\mathrm{Lm} 1 / \mathrm{Lm} 2$ varies from 1.02 to 1.12 ; the ratio LM1/LM2 varies from 1.02 to 1.14; the ratios $\mathrm{Lm} 2 / \mathrm{Lm} 3$ and LM2/LM3 hardly vary.

Three samples (GAIM, PDES and MIR1) differ from the other samples as their $\mathrm{m} 1$ and $\mathrm{m} 2$ are very similar in length. The same is true for the other samples from MP27 and MP28. From MP29 through MN2 the $\mathrm{m} 1$ is always clearly longer than $\mathrm{m} 2$, also in the samples that are not represented in Figure 13. The only exception is BF53, where the number of specimens is insufficient for a reliable result. The same situation is found for the relation 


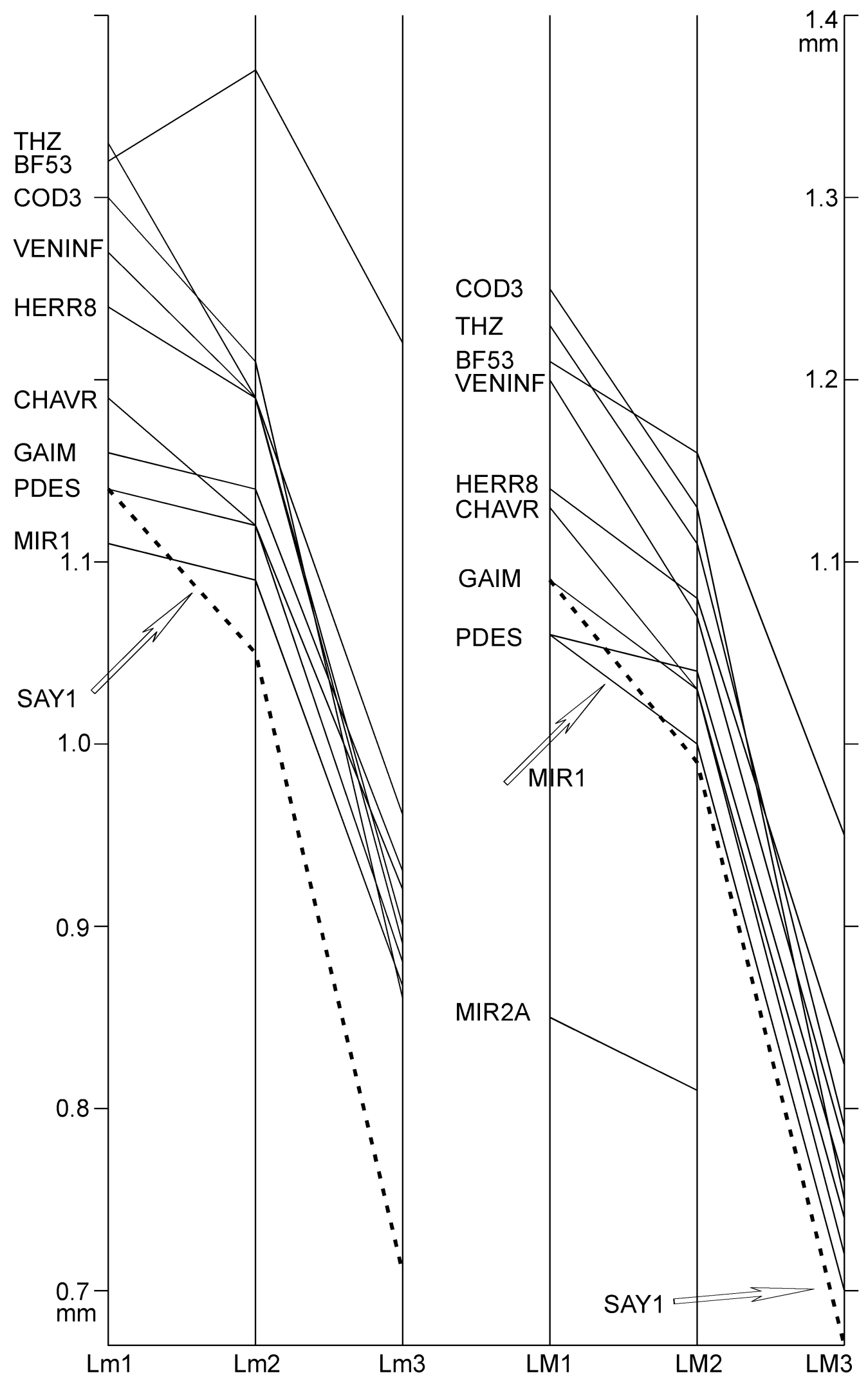

FIGURE 13. Relation of mean length values (in $\mathrm{mm}$ ) of $\mathrm{m} 1, \mathrm{~m} 2, \mathrm{~m} 3, \mathrm{M} 1, \mathrm{M} 2, \mathrm{M} 3$ of Plesiosminthus species. Number of specimens per sample in Table 7. 
TABLE 7. Number of specimens for samples in Figure 13.

\begin{tabular}{lcccccc}
\hline Sample & $\mathbf{m} 1$ & $\mathbf{m} 2$ & $\mathbf{m 3}$ & $\mathbf{M 1}$ & $\mathbf{M} 2$ & $\mathbf{M 3}$ \\
\hline BF53 & 4 & 4 & 5 & 6 & 5 & 5 \\
CHAVR & 36 & 48 & 39 & 49 & 33 & 15 \\
COD3 & 65 & 59 & 32 & 71 & 63 & 13 \\
GAIM & 34 & 32 & 11 & 28 & 23 & 3 \\
HERR8 & 8 & 15 & 14 & 18 & 12 & 11 \\
MIR1 & 17 & 41 & 45 & 49 & 43 & 37 \\
PDES & 57 & 54 & 16 & 35 & 16 & 3 \\
SAY1 & 7 & 6 & 1 & 3 & 3 & 1 \\
THZ & 142 & 123 & 97 & 119 & 111 & 87 \\
VENINF & 19 & 25 & 8 & 27 & 26 & 1 \\
\hline
\end{tabular}

M1/M2, with two exceptions: BF53 and LAUT2. Some authors (e.g., Daxner-Höck and Wu, 2003) use the relation $\mathrm{M} 1 / \mathrm{M} 3$ and $\mathrm{m} 1 / \mathrm{m} 3$. However, third molars are often scarce, and their mean length may be less reliable than that of the first molars. We prefer comparing first and second molars.

\section{PHYLOGENY}

Until now all authors considered $P$. myarion to be a descendant of $P$. promyarion. But that was at a time when these two were practically the only species known. The evolution would be marked by a slight size increase, a moderately derived protoconid hind arm of $\mathrm{m} 2$ and a strongly derived protolophule of M2. In view of the impossibility to know what exactly is $P$. promyarion, we tried to identify a possible ancestor of $P$. myarion among the available species. The species from MP30, closest in time to $P$. myarion, can be excluded as its ancestors: P. winistoerferi and $P$. schaubi are larger and $P$. admyarion and $P$. meridionalis are morphologically different. On the other hand, almost any of the older species (MP27/28) is a potential ancestor, both by size and morphology. This difficulty to designate the most probable ancestor in the latest Oligocene was already observed by Hugueney and Vianey-Liaud (1980, figure 7), and in spite of our enlarged knowledge this situation remains unchanged.

Among the MP30 species $P$. admyarion may be closely related to $P$. schaubi; both are characterized by the very low MV values for the protolophule of M2, combined with very high values for the pcdha of $\mathrm{m} 2$. Their size is quite similar, as well as the length relation of $\mathrm{M} 1 / \mathrm{M} 2$ and $\mathrm{m} 1 / \mathrm{m} 2$ (Figures 7-13). On the other hand, P. meridionalis, originally described as a subspecies of $P$. schaubi, is charac- terized by the very high MV values of both $\mathrm{m} 2$ and M2 (Figure 2), and a close relationship with $P$. admyarion is not probable.

Plesiosminthus conjunctus from HERR8 and $P$. aff. conjunctus from MIR2A share very low MV values for $\mathrm{m} 2$ with quite high values for M2 (Figure 2). In this respect, they differ from all other species and an ancestor-descendant relationship is possible. The other species occupy intermediate positions, and nothing can be said about their relationships.

\section{CONCLUSIONS}

Plesiosminthus promyarion Schaub, 1930 is restricted to the two specimens from Puy-de-Montdoury. The name should no longer be used, except when referring to its type material. The single M2 from Rickenbach does not permit classification. Plesiosminthus bavaricus Freudenberg, 1941, considered a synonym of $P$. promyarion by several authors, is here recognized as a different species. The sample from Pech Desse, described as P. promyarion by Hugueney and Vianey-Liaud (1980), is transferred to the new species $P$. moniqueae $\mathrm{n}$. $\mathrm{sp}$. Other supposed $P$. promyarion samples are provisionally called $P$. promyarion Auctorum. Analysis of the morphology values shows surprising mixtures of primitive and advanced states of characters that make it almost impossible to draw conclusions on ancestor-descendant relationships.

\section{ACKNOWLEDGEMENTS}

We are grateful to M. Vianey-Liaud (Montpellier) and J.A. Gallardo (Granada) for information on t-test statistics. G. Roessner (Munich) provided information on the holotype of $P$. bavaricus. Thanks are due to $\mathrm{H}$. de Bruijn (Utrecht) and an anonymous referee for their valuable comments. We thank the editorial team of Palaeontologia Electronica for improving this paper considerably. This study was supported by the research group RNM190 of the Junta de Andalucía.

\section{REFERENCES}

Alvarez Sierra, M.A., Daams, R., and Lacomba Andueza, J.I. 1996. The rodents from the Upper Oligocene of Sayatón 1, Madrid Basin (Guadalajara, Spain). Proceedings Koninklijke Nederlandse Akademie van Wetenschappen, 99(1-2):1-23.

Alvarez Sierra, M.A., Daams, R., and Peláez-Campomanes, P. 1999. The Late Oligocene rodent faunas of Canales (MP28) and Parrales (MP29) from the 
Loranca Basin, province of Cuenca, Spain. Revista Española de Paleontología, 14(1):93-116.

Baudelot, S. and Olivier, P. 1978. Les rongeurs (Mammalia, Rodentia) de l'Oligocène terminal de Dieupentale (Sud-Ouest de la France: Tarn-et-Garonne). Géobios, 11(1):5-19.

Biochrom'97. 1997. Syntheses and correlation tables. Mémoires Travaux E.P.H.E., Institut Montpellier, 21:337-352.

Bowdich, T.E. 1821. Analysis of the Natural Classifications of Mammalia for the Use of Students and Travellers. J. Smith, Paris.

Comte, B. 2000. Rythme et modalités de l'évolution chez les ronguers à la fin de l'Oligocène. Leurs relations avec les changements de l'environnement. Palaeovertebrata, 29(2-4):83-360.

Daxner-Höck, G. and Wu, W. 2003. Plesiosminthus (Zapodidae, Mammalia) from China and Mongolia: migrations to Europe. Deinsea, 10:127-151.

Engesser, B. 1987. New Eomyidae, Dipodidae, and Cricetidae (Rodentia, Mammalia) of the Lower Freshwater Molasse of Switzerland and Savoy. Eclogae Geologicae Helvetiae, 80(3):943-994.

Engesser, B. and Mödden, C. 1997. A new version of the biozonation of the Lower Freshwater Molasse (Oligocene and Agenian) of Switzerland and Savoy on the basis of fossil mammals. Mémoires Travaux E.P.H.E., Institut Montpellier, 21:475-499.

Engesser, B. and Storch, G. 2008. Latest Oligocene Didelphimorphia, Lipotyphla, Rodentia and Lagomorpha (Mammalia) from Oberleichtersbach, Rhön Mountains, Germany. Courier Forschungsinstitut Senckenberg, 260:185-251.

Fischer, G. 1817. Adversaria zoologica. Mémoires de la Société Impériale des Naturalistes de Moscou, 5:357-472.

Freudenberg, H. 1941. Die oberoligocänen Nager von Gaimersheim bei Ingolstadt und ihre Verwandten. Palaeontographica, 92A:99-164.

Freudenthal, M. 1994. Cricetidae (Rodentia, Mammalia) from the Upper Oligocene of Mirambueno and Vivel del Río (Teruel, Spain). Scripta Geologica, 104:1-55.

Freudenthal, M. 1997. Paleogene rodent faunas from the province of Teruel (Spain). Mémoires Travaux E.P.H.E., Institut Montpellier, 21:397-415.

Freudenthal, M. 2004. Gliridae (Rodentia, Mammalia) from the Eocene and Oligocene of the Sierra Palomera (Teruel, Spain). Treballs del Museu de Geologia de Barcelona, 12:97-173.

Freudenthal, M. and Cuenca Bescós, G. 1984. Size variation of fossil rodent populations. Scripta Geologica, 76:1-28.

Freudenthal, M., Hugueney, M., and Moissenet, E. 1994. The genus Pseudocricetodon (Cricetidae, Mammalia) in the Upper Oligocene of the province of Teruel (Spain). Scripta Geologica, 104:57-114.
Hugueney, M. 1969. Les rongeurs (Mammalia) de l'Oligocène supérieur de Coderet-Bransat (Allier). Documents Laboratoire Géologie Faculté des Sciences Lyon, 34:1-227.

Hugueney, M., Adrover, R., Moissenet, E., and SchmidtKittler, N. 1987. Les Mammifères de Vivel del Río (prov. de Teruel, Espagne; Oligocène supérieur): un riche gisement stratifié en comparaison avec des faunes karstiques. Münchner Geowissenschaftliche Abhandlungen, A, 10:117-130.

Hugueney, M. and Vianey-Liaud, M. 1980. Les Dipodidae (Mammalia, Rodentia) d'Europe Occidentale au Paleogène et au Neogène inferieur: Origine et evolution. Palaeovertebrata, Mémoire Jubilaire R. Lavocat, 9:303-342.

Hutterer, R. 2003. Two replacement names and a note on the author of the shrew family Soricidae (Mammalia). Bonner Zoologische Beiträge, 50:369-370.

International Commission on Zoological Nomenclature. 1999. International Code of Zoological Nomenclature (4th edition). International Trust for Zoological Nomenclature, London.

Kimura, Y. 2013. Intercontinental dispersals of sicistine rodents (Sicistinae, Dipodidae, Rodentia) between Eurasia and North America, p. 656-673. In Wang, X., Flynn, L., and Fortelius, M. (eds.), Mammalian Biostratigraphy and Chronology of Asia. Columbia University Press, New York.

Kristkoiz, A. 1992. Zahnmorphologische und schädelanatomische Untersuchungen an Nagetieren aus dem Oberoligozän von Gaimersheim (Süddeutschland). Abhandlungen der Bayerischen Akademie der Wissenschaften, mathematisch-naturwissenschaftliche Klasse, neue Folge, 167:1-137.

Schaub, S. 1925. Die hamsterartigen Nagetiere des Tertiärs und ihre lebenden Verwandten. Abhandlungen der Schweizerischen Paläontologischen Gesellschaft, 45:1-114.

Schaub, S. 1930. Fossile Sicistinae. Eclogae geologicae Helvetiae, 23(2):616-636.

Viret, J. 1926. Nouvelles observations relatives à la faune de rongeurs de St Gérand-le-Puy. Comptes rendus Académie des Sciences, Paris, 183:71-72.

Wood, A.E. and Wilson, R.W. 1936. A suggested nomenclature for the cusps of the cheek teeth of rodents. Journal of Paleontology, 10:388-391.

Ziegler, R. 1994. Rodentia (Mammalia) aus den oberoligozänen Spaltenfüllungen Herrlingen 8 und Herrlingen 9 bei Ulm (Baden-Württemberg). Stuttgarter Beiträge Naturkunde, B, 196:1-81.

Ziegler, R. and Werner, J. 1994. Die Kleinsäugerfauna von Lautern 2 bei Ulm - Ein Beitrag zur Biostratigraphie der Unteren Süsswasser-Molasse Süddeutschlands. Stuttgarter Beiträge Naturkunde, B, 207:1-69. 
APPENDIX 1.

Measurements of Plesiosminthus samples. V' = coefficient of variation as defined by Freudenthal and Cuenca Bescos (1984): 100R/M, where $R$ is the range, and $M$ is the median of the distribution. $\sigma=$ standard deviation.

\begin{tabular}{|c|c|c|c|c|c|c|c|c|c|c|c|c|}
\hline \multirow[b]{2}{*}{ m1 } & \multicolumn{6}{|c|}{ Length } & \multicolumn{6}{|c|}{ Width } \\
\hline & $\mathbf{N}$ & Min. & Mean & Max. & $\mathbf{V}^{\prime}$ & $\sigma$ & $\mathbf{N}$ & Min. & Mean & Max. & $\mathbf{V}^{\prime}$ & $\sigma$ \\
\hline CLUZEL & 10 & 1.13 & 1.210 & 1.32 & 15.5 & 0.055 & 10 & 0.76 & 0.830 & 0.93 & 20.1 & 0.046 \\
\hline CHAVR & 36 & 1.09 & 1.190 & 1.31 & 18.3 & 0.013 & 36 & 0.75 & 0.870 & 0.97 & 25.6 & 0.049 \\
\hline LAUT2 & 19 & 1.20 & 1.260 & 1.39 & 14.7 & 0.053 & 25 & 0.82 & 0.890 & 0.92 & 11.5 & 0.042 \\
\hline SAULC & 15 & 1.07 & 1.260 & 1.39 & 26.0 & 0.059 & 15 & 0.79 & 0.880 & 0.94 & 17.3 & 0.044 \\
\hline FORN11 & 27 & 1.08 & 1.222 & 1.36 & 23.0 & 0.063 & 27 & 0.76 & 0.856 & 0.92 & 19.0 & 0.042 \\
\hline VENINF & 19 & 1.13 & 1.270 & 1.39 & 20.6 & 0.064 & 19 & 0.83 & 0.910 & 1.02 & 20.5 & 0.058 \\
\hline BF53 & 4 & 1.30 & 1.320 & 1.34 & 3.0 & 0.016 & 4 & 0.96 & 1.035 & 1.08 & 11.8 & 0.054 \\
\hline $\mathrm{THZ}$ & 142 & 1.19 & 1.330 & 1.47 & 21.1 & 0.062 & 142 & 0.82 & 0.920 & 1.02 & 21.7 & 0.045 \\
\hline COD3 & 65 & 1.18 & 1.300 & 1.44 & 19.8 & 0.066 & 65 & 0.86 & 0.960 & 1.06 & 20.8 & 0.046 \\
\hline DIEU & 33 & 1.15 & 1.28 & 1.40 & 19.6 & & 33 & 0.82 & 0.93 & 1.04 & 23.7 & \\
\hline PARR & 15 & 1.17 & 1.280 & 1.44 & 20.7 & & 16 & 0.86 & 0.940 & 1.12 & 26.3 & \\
\hline SAY1 & 7 & 1.07 & 1.140 & 1.22 & 13.1 & & 8 & 0.70 & 0.750 & 0.79 & 12.1 & \\
\hline HERR8 & 8 & 1.17 & 1.240 & 1.33 & 12.8 & & 8 & 0.82 & 0.879 & 0.96 & 15.7 & \\
\hline PDF & 45 & 1.06 & 1.150 & 1.26 & 17.2 & 0.049 & 45 & 0.74 & 0.820 & 0.92 & 21.7 & 0.043 \\
\hline PDES & 57 & 0.98 & 1.140 & 1.23 & 22.6 & 0.049 & 58 & 0.67 & 0.800 & 0.88 & 27.1 & 0.039 \\
\hline GAIM & 34 & 1.05 & 1.160 & 1.25 & 17.4 & 0.051 & 34 & 0.73 & 0.840 & 0.94 & 25.1 & 0.051 \\
\hline RDUBEY & 19 & 1.04 & 1.109 & 1.20 & 14.3 & 0.051 & 19 & 0.68 & 0.792 & 0.88 & 25.6 & 0.057 \\
\hline VIV1 & 42 & 1.02 & 1.109 & 1.23 & 18.7 & 0.062 & 47 & 0.68 & 0.776 & 0.88 & 25.6 & 0.050 \\
\hline MIR2A & 17 & 1.02 & 1.125 & 1.22 & 17.9 & 0.051 & 18 & 0.72 & 0.808 & 0.89 & 21.1 & 0.035 \\
\hline MIR1 & 17 & 1.02 & 1.119 & 1.19 & 15.4 & 0.056 & 21 & 0.72 & 0.796 & 0.85 & 16.6 & 0.039 \\
\hline $\mathrm{m} 2$ & $\mathbf{N}$ & Min. & Mean & Max. & $\mathbf{V}^{\prime}$ & $\sigma$ & $\mathbf{N}$ & Min. & Mean & Max. & $\mathbf{V}^{\prime}$ & $\sigma$ \\
\hline CLUZEL & 8 & 1.10 & 1.170 & 1.26 & 13.6 & 0.058 & 8 & 0.88 & 0.930 & 0.98 & 10.8 & 0.033 \\
\hline CHAVR & 48 & 1.02 & 1.120 & 1.22 & 17.9 & 0.050 & 48 & 0.82 & 0.930 & 1.00 & 19.8 & 0.041 \\
\hline LAUT2 & 28 & 1.10 & 1.160 & 1.22 & 10.3 & 0.034 & 29 & 0.86 & 0.950 & 1.01 & 16.0 & 0.048 \\
\hline SAULC & 24 & 1.07 & 1.170 & 1.28 & 17.9 & 0.057 & 24 & 0.82 & 0.920 & 1.02 & 21.7 & 0.050 \\
\hline FORN11 & 24 & 1.00 & 1.116 & 1.20 & 18.2 & 0.052 & 24 & 0.77 & 0.898 & 0.98 & 24.0 & 0.054 \\
\hline VENINF & 25 & 1.07 & 1.190 & 1.30 & 19.4 & 0.049 & 24 & 0.88 & 0.950 & 1.00 & 12.8 & 0.041 \\
\hline BF53 & 4 & 1.34 & 1.373 & 1.40 & 4.4 & 0.032 & 4 & 1.04 & 1.048 & 1.06 & 1.9 & 0.010 \\
\hline $\mathrm{THZ}$ & 123 & 1.01 & 1.190 & 1.33 & 27.4 & 0.065 & 123 & 0.83 & 0.950 & 1.09 & 27.1 & 0.051 \\
\hline COD3 & 59 & 1.09 & 1.210 & 1.34 & 20.6 & 0.055 & 59 & 0.86 & 0.990 & 1.09 & 23.6 & 0.049 \\
\hline DIEU & 30 & 1.05 & 1.17 & 1.28 & 19.7 & & 30 & 0.82 & 0.92 & 1.02 & 21.7 & \\
\hline PARR & 13 & 1.03 & 1.190 & 1.35 & 26.9 & & 16 & 0.84 & 0.960 & 1.11 & 27.7 & \\
\hline SAY1 & 6 & 0.95 & 1.050 & 1.15 & 19.0 & & 6 & 0.77 & 0.840 & 0.89 & 14.5 & \\
\hline HERR8 & 15 & 1.16 & 1.197 & 1.26 & 8.3 & & 15 & 0.85 & 0.923 & 1.00 & 16.2 & \\
\hline PDF & 28 & 0.99 & 1.140 & 1.25 & 23.2 & 0.067 & 28 & 0.79 & 0.880 & 0.98 & 21.5 & 0.047 \\
\hline PDES & 54 & 0.99 & 1.120 & 1.23 & 21.6 & 0.048 & 54 & 0.79 & 0.850 & 0.94 & 17.3 & 0.038 \\
\hline GAIM & 32 & 1.05 & 1.140 & 1.21 & 14.2 & 0.041 & 31 & 0.79 & 0.870 & 0.96 & 19.4 & 0.039 \\
\hline RDUBEY & 9 & 1.00 & 1.106 & 1.18 & 16.5 & 0.066 & 9 & 0.80 & 0.841 & 0.90 & 11.8 & 0.044 \\
\hline VIV1 & 51 & 0.96 & 1.063 & 1.17 & 19.7 & 0.050 & 52 & 0.73 & 0.842 & 0.92 & 23.0 & 0.046 \\
\hline MIR2A & 16 & 1.05 & 1.116 & 1.21 & 14.2 & 0.048 & 18 & 0.83 & 0.893 & 0.94 & 12.4 & 0.032 \\
\hline
\end{tabular}


Appendix 1 (continued).

\begin{tabular}{|c|c|c|c|c|c|c|c|c|c|c|c|c|}
\hline \multirow[b]{2}{*}{ MIR1 } & \multicolumn{6}{|c|}{ Length } & \multicolumn{6}{|c|}{ Width } \\
\hline & 41 & 0.99 & 1.093 & 1.17 & 16.7 & 0.041 & 42 & 0.78 & 0.869 & 0.98 & 22.7 & 0.041 \\
\hline $\mathrm{m} 3$ & $\mathbf{N}$ & Min. & Mean & Max. & V' & $\sigma$ & $\mathbf{N}$ & Min. & Mean & Max. & $\mathbf{V}^{\prime}$ & $\sigma$ \\
\hline CLUZEL & 13 & 0.83 & 0.920 & 0.99 & 17.6 & 0.044 & 13 & 0.75 & 0.820 & 0.88 & 16.0 & 0.043 \\
\hline CHAVR & 39 & 0.78 & 0.880 & 0.99 & 23.7 & 0.056 & 39 & 0.68 & 0.790 & 0.90 & 27.8 & 0.047 \\
\hline LAUT2 & 26 & 0.88 & 0.960 & 1.04 & 16.7 & 0.051 & 26 & 0.75 & 0.820 & 0.90 & 18.2 & 0.044 \\
\hline SAULC & 18 & 0.90 & 0.950 & 1.05 & 15.4 & 0.036 & 18 & 0.76 & 0.810 & 0.89 & 15.8 & 0.040 \\
\hline FORN11 & 18 & 0.80 & 0.928 & 1.00 & 22.2 & 0.042 & 18 & 0.68 & 0.799 & 0.86 & 23.4 & 0.043 \\
\hline VENINF & 8 & 0.82 & 0.900 & 0.98 & 17.8 & 0.052 & 8 & 0.70 & 0.780 & 0.84 & 18.2 & 0.046 \\
\hline BF53 & 5 & 1.16 & 1.220 & 1.32 & 12.9 & 0.062 & 5 & 0.98 & 1.032 & 1.10 & 11.5 & 0.063 \\
\hline $\mathrm{THZ}$ & 97 & 0.73 & 0.890 & 1.01 & 32.2 & 0.049 & 97 & 0.70 & 0.800 & 0.97 & 32.3 & 0.052 \\
\hline COD3 & 32 & 0.74 & 0.860 & 0.99 & 28.9 & 0.053 & 32 & 0.70 & 0.800 & 0.88 & 22.8 & 0.045 \\
\hline DIEU & 20 & 0.68 & 0.79 & 0.90 & 27.8 & & 20 & 0.70 & 0.77 & 0.84 & 18.2 & \\
\hline PARR & 2 & 0.84 & 0.890 & 0.94 & 11.2 & & 3 & 0.81 & 0.850 & 0.88 & 8.3 & \\
\hline SAY1 & 1 & & 0.710 & & & & 1 & & 0.650 & & & \\
\hline HERR8 & 14 & 0.92 & 0.961 & 1.05 & 13.2 & & 14 & 0.76 & 0.819 & 0.87 & 13.5 & \\
\hline PDF & 21 & 0.83 & 0.950 & 1.08 & 26.2 & 0.057 & 21 & 0.71 & 0.790 & 0.88 & 21.4 & 0.046 \\
\hline PDES & 16 & 0.86 & 0.920 & 1.00 & 15.1 & 0.041 & 14 & 0.68 & 0.750 & 0.81 & 17.4 & 0.037 \\
\hline GAIM & 11 & 0.81 & 0.930 & 0.99 & 20.0 & 0.050 & 11 & 0.72 & 0.780 & 0.80 & 10.5 & 0.024 \\
\hline RDUBEY & 6 & 0.80 & 0.883 & 0.92 & 14.0 & 0.043 & 6 & 0.72 & 0.760 & 0.82 & 13.0 & 0.044 \\
\hline VIV1 & 39 & 0.76 & 0.839 & 0.94 & 21.2 & 0.045 & 40 & 0.63 & 0.724 & 0.82 & 26.2 & 0.044 \\
\hline MIR2A & 20 & 0.79 & 0.867 & 0.96 & 19.4 & 0.051 & 20 & 0.68 & 0.773 & 0.89 & 26.8 & 0.056 \\
\hline MIR1 & 45 & 0.78 & 0.867 & 0.99 & 23.7 & 0.046 & 45 & 0.67 & 0.773 & 0.86 & 24.8 & 0.045 \\
\hline P4 & $\mathbf{N}$ & Min. & Mean & Max. & $\mathbf{V}^{\prime}$ & $\sigma$ & $\mathbf{N}$ & Min. & Mean & Max. & $\mathbf{V}^{\prime}$ & $\sigma$ \\
\hline CLUZEL & 7 & 0.47 & 0.550 & 0.60 & 24.3 & 0.042 & 7 & 0.49 & 0.560 & 0.65 & 28.1 & 0.038 \\
\hline CHAVR & 18 & 0.36 & 0.470 & 0.60 & 50.0 & 0.051 & 18 & 0.43 & 0.530 & 0.65 & 40.7 & 0.049 \\
\hline SAULC & 21 & 0.40 & 0.480 & 0.58 & 36.7 & 0.053 & 21 & 0.42 & 0.520 & 0.64 & 41.5 & 0.054 \\
\hline $\mathrm{THZ}$ & 34 & 0.47 & 0.610 & 0.71 & 40.7 & 0.043 & 34 & 0.57 & 0.650 & 0.73 & 24.6 & 0.035 \\
\hline COD3 & 29 & 0.48 & 0.590 & 0.66 & 31.6 & 0.040 & 29 & 0.51 & 0.620 & 0.73 & 35.5 & 0.049 \\
\hline GAIM & 1 & & 0.500 & & & & 1 & & 0.600 & & & \\
\hline VIV1 & 7 & 0.49 & 0.536 & 0.59 & 18.5 & 0.036 & 7 & 0.52 & 0.559 & 0.60 & 14.3 & 0.027 \\
\hline MIR2A & 2 & 0.56 & 0.565 & 0.57 & 1.8 & & 2 & 0.47 & 0.505 & 0.54 & 13.9 & \\
\hline MIR1 & 1 & & 0.540 & & & & 1 & & 0.590 & & & \\
\hline M1 & $\mathbf{N}$ & Min. & Mean & Max. & $\mathbf{V}^{\prime}$ & $\sigma$ & $\mathbf{N}$ & Min. & Mean & Max. & $\mathbf{V}^{\prime}$ & $\sigma$ \\
\hline CLUZEL & 17 & 1.09 & 1.160 & 1.30 & 17.6 & 0.053 & 17 & 0.95 & 1.040 & 1.11 & 15.5 & 0.043 \\
\hline CHAVR & 49 & 1.06 & 1.130 & 1.23 & 14.8 & 0.044 & 49 & 0.93 & 1.030 & 1.14 & 20.3 & 0.056 \\
\hline LAUT2 & 20 & 1.04 & 1.150 & 1.26 & 19.1 & 0.054 & 18 & 0.95 & 1.030 & 1.12 & 16.4 & 0.049 \\
\hline SAULC & 28 & 1.06 & 1.150 & 1.25 & 16.5 & 0.047 & 28 & 0.90 & 1.030 & 1.15 & 24.4 & 0.055 \\
\hline FORN11 & 30 & 1.04 & 1.150 & 1.26 & 19.1 & 0.050 & 30 & 0.96 & 1.036 & 1.12 & 15.4 & 0.053 \\
\hline VENINF & 27 & 1.08 & 1.200 & 1.30 & 18.5 & 0.049 & 27 & 0.98 & 1.080 & 1.19 & 19.4 & 0.049 \\
\hline BF53 & 6 & 1.14 & 1.217 & 1.38 & 19.0 & 0.089 & 6 & 0.97 & 1.122 & 1.24 & 24.4 & 0.088 \\
\hline THZ & 119 & 1.06 & 1.230 & 1.36 & 24.8 & 0.058 & 119 & 0.99 & 1.140 & 1.28 & 25.6 & 0.059 \\
\hline COD3 & 71 & 1.14 & 1.250 & 1.39 & 19.8 & 0.051 & 71 & 1.06 & 1.160 & 1.34 & 23.3 & 0.052 \\
\hline DIEU & 30 & 1.14 & 1.22 & 1.30 & 13.1 & & 30 & 1.02 & 1.15 & 1.28 & 22.6 & \\
\hline
\end{tabular}


Appendix 1 (continued).

\begin{tabular}{|c|c|c|c|c|c|c|c|c|c|c|c|c|}
\hline \multirow[b]{2}{*}{ PARR } & \multicolumn{6}{|c|}{ Length } & \multicolumn{6}{|c|}{ Width } \\
\hline & 13 & 1.09 & 1.220 & 1.37 & 22.8 & & 13 & 0.98 & 1.120 & 1.22 & 21.8 & \\
\hline SAY1 & 3 & 1.03 & 1.090 & 1.14 & 10.1 & & 2 & 0.94 & 0.970 & 1.00 & 6.2 & \\
\hline HERR8 & 18 & 1.04 & 1.139 & 1.21 & 15.1 & & 18 & 1.00 & 1.111 & 1.21 & 19.0 & \\
\hline PDF & 30 & 0.96 & 1.080 & 1.22 & 23.9 & 0.067 & 30 & 0.90 & 1.010 & 1.17 & 26.1 & 0.065 \\
\hline PDES & 35 & 1.00 & 1.060 & 1.15 & 14.0 & 0.035 & 35 & 0.87 & 0.960 & 1.02 & 15.9 & 0.035 \\
\hline GAIM & 28 & 1.01 & 1.090 & 1.18 & 15.5 & 0.044 & 28 & 0.93 & 1.010 & 1.10 & 16.7 & 0.045 \\
\hline RDUBEY & 12 & 0.88 & 1.023 & 1.13 & 24.9 & 0.088 & 12 & 0.84 & 0.948 & 1.08 & 25.0 & 0.080 \\
\hline VIV1 & 70 & 0.93 & 1.050 & 1.18 & 23.7 & 0.049 & 69 & 0.85 & 0.970 & 1.10 & 25.6 & 0.048 \\
\hline MIR2A & 30 & 0.96 & 1.075 & 1.19 & 21.4 & 0.050 & 32 & 0.83 & 0.973 & 1.10 & 28.0 & 0.049 \\
\hline MIR1 & 49 & 0.93 & 1.062 & 1.16 & 22.0 & 0.048 & 51 & 0.85 & 0.962 & 1.11 & 26.5 & 0.051 \\
\hline M2 & $\mathbf{N}$ & Min. & Mean & Max. & $\mathbf{V}^{\prime}$ & $\boldsymbol{\sigma}$ & $\mathbf{N}$ & Min. & Mean & Max. & $\mathbf{V}^{\prime}$ & $\boldsymbol{\sigma}$ \\
\hline CLUZEL & 18 & 0.92 & 1.020 & 1.11 & 18.7 & 0.052 & 17 & 0.88 & 0.980 & 1.10 & 22.2 & 0.054 \\
\hline CHAVR & 33 & 0.98 & 1.030 & 1.12 & 13.3 & 0.057 & 33 & 0.88 & 1.000 & 1.10 & 22.2 & 0.057 \\
\hline LAUT2 & 26 & 0.98 & 1.080 & 1.16 & 16.8 & 0.047 & 28 & 0.93 & 1.030 & 1.09 & 15.8 & 0.049 \\
\hline SAULC & 21 & 0.96 & 1.050 & 1.16 & 18.9 & 0.051 & 21 & 0.91 & 1.010 & 1.08 & 17.1 & 0.048 \\
\hline FORN11 & 16 & 0.92 & 1.016 & 1.10 & 17.8 & 0.055 & 16 & 0.88 & 0.959 & 1.06 & 18.6 & 0.058 \\
\hline VENINF & 26 & 0.96 & 1.070 & 1.17 & 19.7 & 0.057 & 24 & 0.94 & 1.000 & 1.06 & 12.0 & 0.036 \\
\hline BF53 & 5 & 1.10 & 1.164 & 1.22 & 10.3 & 0.048 & 5 & 1.07 & 1.134 & 1.18 & 9.8 & 0.040 \\
\hline THZ & 111 & 0.96 & 1.110 & 1.25 & 26.2 & 0.065 & 111 & 0.89 & 1.020 & 1.13 & 23.8 & 0.051 \\
\hline COD3 & 63 & 1.01 & 1.130 & 1.24 & 20.4 & 0.054 & 63 & 0.97 & 1.070 & 1.21 & 22.0 & 0.046 \\
\hline DIEU & 26 & 1.00 & 1.10 & 1.20 & 18.2 & & 26 & 0.97 & 1.08 & 1.20 & 21.2 & \\
\hline PARR & 14 & 1.01 & 1.100 & 1.17 & 14.7 & & 14 & 0.91 & 1.060 & 1.18 & 25.8 & \\
\hline SAY1 & 3 & 0.95 & 0.990 & 1.05 & 10.0 & & 3 & 0.80 & 0.870 & 0.92 & 14.0 & \\
\hline HERR8 & 12 & 1.02 & 1.085 & 1.18 & 14.5 & & 12 & 1.01 & 1.077 & 1.15 & 13.0 & \\
\hline PDF & 27 & 0.90 & 1.010 & 1.12 & 21.8 & 0.067 & 25 & 0.88 & 0.970 & 1.08 & 20.4 & 0.053 \\
\hline PDES & 16 & 0.95 & 1.040 & 1.12 & 16.4 & 0.050 & 16 & 0.88 & 0.960 & 1.02 & 14.7 & 0.036 \\
\hline GAIM & 23 & 0.99 & 1.030 & 1.10 & 10.5 & 0.034 & 22 & 0.94 & 0.990 & 1.05 & 11.1 & 0.032 \\
\hline RDUBEY & 17 & 0.88 & 1.000 & 1.08 & 20.4 & 0.054 & 17 & 0.84 & 0.951 & 1.05 & 22.2 & 0.051 \\
\hline VIV1 & 74 & 0.87 & 0.982 & 1.15 & 27.7 & 0.049 & 69 & 0.84 & 0.935 & 1.09 & 25.9 & 0.047 \\
\hline MIR2A & 24 & 0.91 & 1.006 & 1.08 & 17.1 & 0.050 & 20 & 0.87 & 0.953 & 1.07 & 20.6 & 0.048 \\
\hline MIR1 & 43 & 0.87 & 1.007 & 1.08 & 21.5 & 0.046 & 44 & 0.84 & 0.967 & 1.10 & 26.8 & 0.054 \\
\hline M3 & $\mathbf{N}$ & Min. & Mean & Max. & $\mathbf{V}^{\prime}$ & $\sigma$ & $\mathbf{N}$ & Min. & Mean & Max. & $\mathbf{V}^{\prime}$ & $\sigma$ \\
\hline CLUZEL & 18 & 0.68 & 0.780 & 0.85 & 22.2 & 0.050 & 18 & 0.76 & 0.840 & 0.90 & 16.9 & 0.036 \\
\hline CHAVR & 15 & 0.66 & 0.740 & 0.86 & 26.3 & 0.055 & 15 & 0.71 & 0.820 & 0.90 & 23.6 & 0.047 \\
\hline LAUT2 & 20 & 0.71 & 0.780 & 0.90 & 23.6 & 0.048 & 19 & 0.78 & 0.850 & 0.94 & 18.6 & 0.049 \\
\hline SAULC & 19 & 0.69 & 0.770 & 0.89 & 25.3 & 0.056 & 19 & 0.77 & 0.840 & 0.95 & 20.9 & 0.052 \\
\hline FORN11 & 7 & 0.72 & 0.774 & 0.82 & 13.0 & 0.034 & 7 & 0.80 & 0.836 & 0.90 & 11.8 & 0.038 \\
\hline VENINF & 1 & & 0.780 & & & & 1 & & 0.780 & & & \\
\hline BF53 & 5 & 0.92 & 0.950 & 1.02 & 10.3 & 0.040 & 5 & 0.96 & 1.022 & 1.12 & 15.4 & 0.067 \\
\hline $\mathrm{THZ}$ & 87 & 0.67 & 0.790 & 0.90 & 29.3 & 0.044 & 87 & 0.65 & 0.800 & 0.89 & 31.2 & 0.045 \\
\hline COD3 & 13 & 0.63 & 0.750 & 0.79 & 22.5 & 0.048 & 13 & 0.68 & 0.760 & 0.86 & 23.4 & 0.053 \\
\hline DIEU & 6 & 0.61 & 0.70 & 0.78 & 24.5 & & 6 & 0.66 & 0.75 & 0.84 & 24.0 & \\
\hline PARR & 2 & 0.79 & 0.830 & 0.87 & 9.6 & & 2 & 0.83 & 0.890 & 0.95 & 13.5 & \\
\hline
\end{tabular}


Appendix 1 (continued).

\begin{tabular}{lcccccccccccc}
\hline \multicolumn{1}{c}{ Length } \\
\hline SAY1 & 1 & & 0.670 & & & & 1 & & 0.730 & & \multicolumn{7}{c}{ Width } \\
HERR8 & 11 & 0.74 & 0.824 & 0.89 & 18.4 & & 11 & 0.82 & 0.882 & 0.94 & 13.6 \\
PDF & 9 & 0.68 & 0.750 & 0.82 & 18.7 & 0.046 & 9 & 0.71 & 0.780 & 0.85 & 17.9 & 0.044 \\
PDES & 3 & 0.74 & 0.760 & 0.77 & 4.0 & 0.015 & 3 & 0.74 & 0.770 & 0.79 & 6.5 & 0.025 \\
GAIM & 3 & 0.63 & 0.720 & 0.85 & 29.7 & & 2 & 0.82 & 0.860 & 0.89 & 8.2 & \\
RDUBEY & 4 & 0.64 & 0.738 & 0.80 & 22.2 & 0.068 & 4 & 0.72 & 0.773 & 0.81 & 11.8 & 0.041 \\
VIV1 & 31 & 0.63 & 0.698 & 0.83 & 27.4 & 0.051 & 29 & 0.66 & 0.733 & 0.81 & 20.4 & 0.041 \\
MIR2A & 15 & 0.60 & 0.702 & 0.76 & 23.5 & 0.047 & 16 & 0.71 & 0.783 & 0.84 & 16.8 & 0.039 \\
MIR1 & 37 & 0.63 & 0.700 & 0.77 & 20.0 & 0.035 & 37 & 0.70 & 0.772 & 0.86 & 20.5 & 0.038 \\
\hline
\end{tabular}

